\title{
Memorias de alemanes en España durante la Guerra de la Independencia. La estancia de Philipp Schwein en la isla de Cabrera
}

\author{
Hiltrud Friederich-StegmanN
}

Spanien ist ein grosses Haus,

Viele gehen hinein und Wenige kommen heraus. ${ }^{1}$

\section{RESUMEN}

El presente artículo tiene tres objetivos principales. Primero, da una información general de las memorias de alemanes participantes en la Guerra de la Independencia, junto con una relación bibliográfica, añadida como apéndice. En segundo lugar, da a conocer el autor alemán Johann Christian Mämpel que en seis libros, publicados anónimamente, cuenta las guerras napoleónicas desde el punto de vista del soldado raso, del

Feldjäger. A Goethe le gustó tanto esta obra que escribió el prólogo. Finalmente, el estudio incluye dos traducciones, la de un episodio del tercer tomo, que Mämpel dedica a la estancia de un compañero de guerra como prisionero en la desierta isla de Cabrera, y también la de la introducción de Goethe al mismo tomo con sus reflexiones sobre este asunto.

\section{ABSTRACT}

The present article has three main objects. Firstly, it gives a general view of the memoirs written by German participants in the Spanish War of Independence, including an appendix with a related bibliography. Secondly, it introduces the German author Johann Christian Mämpel, who wrote six books, anonimously published, about the Napoleonic Wars from the point of view of the private soldier, the Feldjäger. Goethe was so impressed by it, that he wrote the prologue. Finally, the study includes two translations: an episocie of the third volume, which Mämpel dedicates to a fellow soldier, who was a prisoner of war on the desert island of Cabrera, and also Goethe's introduction to the same volume with his reflections about this event.

Dicho de los soldados suizos al servicio de España. [Mämpel, Johann Christian]: Des jungen Feldjägers Zeitgenosse in preussischen, französischen, englischen und sardinischen Diensten: nach dessen Tagebuche erzählt vorn Feldjäger. Tomo 2 [tomo 6 de la obra completa]. Braunschweig (Im Verlags=Comtoir) 1831 ; pág. 193. 
El presente trabajo tiene tres objetivos principales. Primero, queremos dar una información general de las memorias de alemanes participantes en la Guerra de la Independencia, junto con una relación bibliográfica que añadimos como apéndice. En segundo lugar, nos ha parecido interesante dar a conocer al lector español el autor alemán Johann Christian Mämpel (1792-1862) que en seis libros, publicados anónimamente, cuenta la guerra desde el punto de vista del soldado raso, del Feldjäger. ${ }^{2}$ A Goethe le gustó tanto esta obra que escribió el prólogo. Finalmente hemos traducido un episodio del tercer tomo, que Mämpel dedica a la estancia de un compañero de guerra en la isla de Cabrera. Hemos traducido también la introducción de Goethe al tercer tomo con sus reflexiones sobre este asunto. Para la mejor comprensión de este hecho singular nos ha parecido necesario empezar este último punto con una breve síntesis de la investigación sobre los prisioneros franceses en la isla de Cabrera.

Las memorias son un género especial dentro de la amplia literatura de la Guerra de la Independencia. Algunas cuentan la participación de su autor en la guerra, otras la historia de un ejército, de un regimiento o de la lucha del pueblo, otras se limitan a hechos destacados como el Dos de Mayo de Madrid, a los diversos sitios, a las grandes batallas o a los guerilleros. A veces ocurre que sirven para justificar, idealizar o incluso glorificar los hechos. Por eso hay que ser precavidos a la hora de utilizar estas fuentes. No obstante, a pesar de su subjetividad, queremos decir con Goethe:

Pensamos que lo singular y lo individual nos permite la mejor comprensión del hombre y de los acontecimientos. Por eso deseamos conocer memorias, autobiografías, cartas originales y los restantes documentos de este tipo. ${ }^{3}$

La Guerra de la Independencia está detalladamente estudiada y las memorias, tanto nacionales como extranjeras, o forman parte de estos trabajos, o son objeto de estudios propios, como es el caso, por ejemplo, del libro de Rafael Farias Memorias de la Guerra de la Independencia. Escritas por soldados franceses, publicado en 1920, que no incluye ninguna memoria de soldados alemanes en el ejército francés. Las memorias alemanas tampoco las menciona Jesús de Haro Malpesa en su libro Guerra de la Independencia. Bailén 1808. Memorias y Diarios, publicado en 1999. El autor se sorprende por el gran número de memorias suizas: «Los suizos de la campaña de Andalucía nos han dejado un número desproporcionado de

\footnotetext{
2. Los Feldjäger eran los cazadores, es decir, las tropas ligeras de la infantería. En la actual Bundeswehr son la policía militar.

Prólogo de Goethe, Der Junge Feldjäger [...], tomo 1, pág. V.
} 
memorias, habida cuenta de que fueron algo menos de mil quinientos, repartidos entre los dos bandos. ${ }^{4}$

Pero en esta guerra participaron también muchos alemanes, tanto en los diferentes regimientos suizos ${ }^{5}$ (algunos de ellos al servicio de España, otros al de Francia), como al servicio de Inglaterra en la llamada King's German Legion, que se había formado en 1803 principalmente con oficiales y soldados de Hannover, después de su ocupación por Napoleón. Su historia nos la cuentan Ludlow Beamisch en Geschichte der königlich deutschen Legion [...], publicada en 1832/37, y Bernhard Heinrich Schwertfeger en Geschichte der königl. deutschen Legion von 1803 - 1816, publicada en 1907. En las tropas napoleónicas habia muchos soldados de los territorios ocupados por Francia y de los estados alemanes del Rheinbund (18061813), al cual pertenecían casi todos, salvo Prusia, Austria, Braunschweig y Kurhessen. Por ello en España lucharon alemanes contra alemanes, a veces hermanos contra hermanos, como lo podemos leer, por ejemplo, en las memorias del teniente Wilhelm von Schauroth. ${ }^{6}$ No se sabe cuántos de ellos perdieron su vida en esta guerra, pero se supone que entre unos seis y ocho mil de la King's German Legion y unos veinte mil de los regimientos del Rheinbund. ${ }^{7}$

La participación masiva de los alemanes se refleja en una ola de publicaciones, cuyo impresionante número demuestra que no sólo para los franceses, sino también para los alemanes, «la guerre d'Espagne a été du point de vue chronologique, comme du point de vue de son importance, le premier facteur qui a façonnél'image de l'Espagne [...] au XIXe siécle." ${ }^{8}$ No obstante, estas memorias las excluye Werner Brüggemann de su estudio Die Spanienberichte des 18. und 19. Jahrhunderts und ihre Bedeutung für die Formung und Wandlung des deutschen Spanienbildes, publicado en 1956,

\footnotetext{
"Haro Malpesa, Jesús de, Guerra de la Independencia. Bailén 1808. Memorias y Diarios. Alcázar de San Juan. 1999; pág. 31.

Se llamaron suizos porque sus comandantes eran suizos, pero muchos de los soldados eran alemanes. Su historia está descrita en: MAAG, Albert: Geschichie der Schweizertruppen im Krieg Napoleons I. in Spanien und Portugal (1807-1814). 2 vols. Biel, 1892/93. Según Haro MaLPESA, «en 1808 habia en España tres regimientos suizos, que quedaron repartidos entre los ejércitos españoles y franceses cuando comenzó el conflicto", pág. 30

Schaunoth, Alexander Freiherr von (Ed.), Im Rheinbund-Regiment der Herzoglich Sächsischen Kontingente Koburg=Hildburghausen=Gotha=Weimar während der Feldz,ge in Tirol, Spanien und Russland 1809-1813. Nachden Aufzeichnungen des damaligen Leutnants Wilhelm Freiherr $v$. Schauroth zusammengesteltt. Berlín (Mittler), 1905, pág. 136. Este libro y algunas memorias más se encuentran en la Fundación Biblioteca Alemana Görres de Madrid.

StRICKER, Wilhelm, Die Deutschen in Spanien und Portugal und den spanischen und portugiesischen Ländern von America. Ein Beitrag zur Geschichte der Deutschen ausser Deutschland. Leipzig (Gustav Mayer) 1850, págs. 160 y sig. De los regimientos suizos no da ninguna cifra.

Hoffmann, Léon-François, Romantique Espagne. L'image de l'Espagne en France entre 1800 et 1850. New Jersey-París, 1961; pág. 20.
} 
aduciendo que se trata de un género especial. ${ }^{9}$ Del mismo modo la mayoría de estos libros no figuran en el Diccionario bibliográfico de la Guerra de Independencia españolat ${ }^{10}$ y tampoco en la Bio-Bibliografía de viajeros por España y Portugal (siglo XIX) de Carlos García-Romeral Pérez, publicada en 1999. Por eso nos ha parecido interesante elaborar una relación bibliográfica, que incluimos como apéndice final. Algunos de estos títulos los hemos sacado de la obra bibliográfica de Arturo Farinelli Viajes por España y Portugal $[\ldots],{ }^{11}$ otros del libro de Wilhelm Stricker Die Deutschen in Spanien und Portugal [...] y otros de la amplia bibliografía Memoirs of the Napoleonic Era. ${ }^{12}$ Los hemos comprobado y corregido según el Gesamtverzeichnis des deutschsprachigen Schriftums 1700-1910 [... $]^{3}$, donde hemos encontrado una gran parte de las restantes memorias.

De estas memorias, escritas en su mayoría por oficiales, destaca la obra del joven soldado raso Johann Christian Mämpel, titulada Der Junge Feldjäger in französischen und englischen Diensten während des Spanisch=Portugiesischen Kriegs von 1806-1816 y publicada anónimamente en tres tomos en $1826 .{ }^{14}$ En los dos primeros tomos cuenta su propia historia y en el tercero, que lleva además el título Des Jungen Feldjägers Kriegskamerad gefangen und strandend, immer getrost und thätig, la de su compañero de guerra Philipp Schwein.

Del autor, Johann Christian Mämpel, sólo sabemos lo que él nos cuenta en los dos primeros tomos de dicha obra. El primer capítulo está dedicado a su infancia. Huérfano de padre, un pobre predicador que murió poco después de su nacimiento, creció con su madre y varios hermanos en un pueblo de Sajonia. Era un niño rebelde que siempre soñaba con aventuras. Dotado de muchos talentos, su madre le dejaba estudiar con el fin de que fuera también pastor como su padre. Pero cuando tenía 15 años, murió también su madre. Como su tutor había defraudado su pequeña herencia, no tuvo más remedio que dejar los estudios y aprender un oficio. Decidió hacerse barbero cirujano, pero no pudo acostumbrarse a tratar a los heri-

\footnotetext{
9. Brüggemann, Werner, “Die Spanienberichte des 18. und 19. Jahrhunderts und ihre Bedeutung $f, r$ die Formung und Wandlung des deutschen Spanienbildes", en Spanische Forschungen der G^rresgesellschaft. 1. Reihe, Band 12. M.nster Westfalen (Aschendorff), 1956, págs. 1-146; la cita, en pág. 91 .

Diccionario bibliográfico de la Guerra de Independencia española. 3 vols. Madrid (Servicio Geográfico del Ejército) 1944-1952.

FARINELLI, Arturo, Viajes por España y Portugal. Desde la Edad Media hasta el Siglo XX. Divagáciones Bibliográficas. 2 tomos. Madrid 1920 y 1930. Tomo 1, págs. 337-343; tomo 2, págs. 328-332.

12. Internet: http://napoleonic-literature.com/AgeOfNapoleon/Bibliography/Memoirs.html.

${ }^{13}$ GV Gesamtverzeichnis des deuischsprachigen Schriftums 1700-1910. Bearbeitet unter der Leitung von Peter Geils und Willi Gorzny. Bibliographische und redaktionelle Beratung: Hans Probst und Rainer Schill. 160 vols. Munich, Nueva York, Londres, París (K.G. Saur), 1979-1987.

14. La segunda edición de estos tres primeros tomos data de 1846.
} 
dos y abandonó a su maestro. Tenía 16 años cuando cayó en manos de los alistadores franceses. Al principio no sabía que su destino era España, y cuando se dio cuenta ya era demasiado tarde para desertar.

El 13 de enero de 1808 entró en el norte de España, y en los capítulos dos, tres y cuatro del primer tomo cuenta su estancia y cómo las circunstancias le llevaron por todo el país. Con orgullo recuerda cómo se había dirigido a él Napoleón:

El Emperador Napoleón llegó a Valladolid y pasó revista a todas las tropas estacionadas allí. Al pasar delante del regimiento habló con varios soldados. Debido a mi juventud le debí llamar la atención, así que me dirigió la palabra preguntándome:

Quel, ge as-tu, jeune homme?

Seize ans et demi, Sire.

Vous Ítes encore trop jeune. De quel pays Ítes-Vous?

Je suis Saxon, mon Empereur.

Ah, les Saxons sont toujours de bons soldats et je crois que Vous le serez aussi; pas vrai, mon garçon?

Con estas palabras me dejó para dirigirse a otro. Tenía la costumbre de coger un botón del uniforme de la persona con la que hablaba. También conmigo lo hizo y no me soltó durante todo el tiempo que estuvo hablando conmigo, de modo que estuve a punto de desmayarme. ${ }^{15}$

No obstante, por regla general no habla muy bien de los franceses. Sobre todo le molestan los saqueos:

En nuestra marcha a Valencia no se respetó la propiedad de ninguna casa; incluso robaron las iglesias, a pesar de una rígida orden que lo prohibía tajantemente y del fusilamiento inmediato de algunos soldados cogidos in fraganti. Pero ni siquiera esta suma dureza dio resultado, ya que la codicia superó el miedo al castigo en las tropas francesas. ${ }^{16}$

Recuerda las devastaciones realizadas en la retirada de las tropas al norte de España:

En esta retirada de Madrid nuestro ejército se pareció más a una banda de bandidos que a tropas disciplinadas: las ciudades por las que pasamos fueron quemadas y los pueblos que abandonamos por la mañana generalmente fueron víctimas de las llamas. Se mataron los animales, daba igual si eran necesarios o no para nuestra alimentación. En resumen, se devastó y asoló todo;

\footnotetext{
15. Mämpel, tomo 1, págs. 171 y sig.

${ }^{16}$ Mämpel, tomo 1, pág. 132.
} 
incluso se quemaron los montones de cereales que todavía quedaban en los campos. $^{17}$

El 7 de abril de 1811 Mämpel cayó prisionero de los ingleses en la retirada, después del bloqueo de Almeida, capitulando con ellos. El segundo tomo de la obra, que empieza con el capítulo cinco, está dedicado a su vida con las tropas inglesas, sobre todo a sus estancias en Inglaterra y $\mathrm{Si}$ cilia. Sólo las páginas 107 a 137 tratan de España, a donde regresó desde Sicilia después de haber estado algunos días en Menorca:

Después de un viaje de quince días echamos el ancla en el lugar de nuestro destino, la rada de Alicante. De nuevo me encontraba en la costa de España, pero en mejores condiciones que cuando había dejado el país: entonces estaba muerto de hambre y andrajoso, ahora bien alimentado y bien vestido; entonces pertenecía a los opresores del pueblo, ahora al ejército cuyo destino era la liberación de España del yugo ajeno. ${ }^{18}$

Sus repetidos elogios a los ingleses explican la inmediata traducción de los tres primeros tomos al inglés. ${ }^{19}$

Al final del segundo tomo Mämpel cuenta su regreso a Alemania en 1816. Se instaló en Weimar, donde escribiría su obra. El libro fue muy elogiado por Goethe, que escribió el prólogo. En realidad, son dos prólogos, uno general en el primer tomo, págs. $V$-X, donde recomienda toda la obra, y otro especial, como introducción al tercer tomo, págs. III-VIII. ${ }^{20} \mathrm{~A}$ Goethe le parece recomendable todo el libro, porque "los destinos de todos los hombres se parecen y lo que sucede a uno puede valer de símbolo para miles." $Y$ añade que le gusta captar los sucesos lejanos a través de las realidades singulares:

Sólo cuando una persona ingenua y de poca importancia da testimonio de acontecimientos importantes a los cuales no asistió por curiosidad o intencionadamente, sino forzosamente, porque no le quedó más remedio, se entienden mejor los sucesos de los cuales nos enteramos por los periódicos sólo de una manera general y a menudo muy dudosa.

\footnotetext{
17. Mämpel, tomo 1, pág. 152.

Mämpel, tomo 2, págs. 107 y sig.

${ }^{19}$ Los tomos 4,5 y 6 no se tradujeron, tal vez porque en ellos no se habla tan bien de los ingleses.

De los más de cien libros de alemanes participantes en la Guerra de la Independencia que hemos encontrado, sólo cinco se tradujeron al ingiés.

Los prólogos de Goethe se publicaron también en el tomo 31, págs. 316-321 de Goethe's sämmtliche Werke in vierzig Bänden. Stuttgart (Cotta), 1857. Según Goethe, pág. 323, la obra de Mämpel se reseñó muy positivamente en la Jenaische allgemeine Literatur=Zeitung 22 (1825) y 35 (1827)
} 


\section{Goethe describe al autor de esta manera:}

El Feldjäger tiene buen caracter, acepta todo, es obediente, valiente, constante, bonachón y recto, exceptuando algunos pequeños saqueos, que siempre explica y excusa por la extrema necesidad. En resumen, si uno fuese soldado, desearia tener un compañero así.

Además, a Goethe le parecen de gran interés las múltiples escenas en las que un soldado raso, gracias a su boleta de alojamiento, tiene acceso a las casas particulares e incluso comparte la intimidad de los hogares. Como ejemplo hemos elegido el primer alojamiento de Mämpel en España, que era en una casa muy humilde, a la que llegó hambriento:

El hambre me obligó a dirigirme con palabras y signos al ama, que supo preguntarme de la misma manera si tenía yo pan, ya que por lo visto no había mucho en casa. Después de haberlo sacado, cogió ajo, pimentón y aceite de oliva, los mezcló y añadió agua hirviendo. Mientras tanto yo había cortado el pan y ella echó la salsa encima, elogiándola mucho. Me puse a comer el plato trugal, pero a pesar de mi gran apetito no me gustó nada. No obstante, como no había otra cosa, me lo comí todo. Más tarde me acordé a menudo con gratitud de Doña García por haberme enseñado a preparar esta sopa tan rica, que tomé muchas veces con gran gusto y que me ha mantenido sano. ${ }^{21}$

Mämpel es un buen observador y eso hace muy interesante la lectura de sus libros, como puede demostrar la siguiente escena del segundo tomo:

Recibimos la orden de regresar a nuestros regimientos en Sicilia. Entonces embarcamos cerca de Tarragona, que todavía no estaba en nuestro poder. Llegamos a un barco destinado a las caballerías, que había llevado desde Irlanda a España a los húsares de Braunschweig.

Nuestro viaje en este barco de caballos no fue muy agradable. No teniamos mucho espacio y nos encontrábamos apretados como sardinas en lata, junto con caballos de artilieria, cuyo olor causaba grandes molestias a los que no lo toleraban. Seguro que estos pobres animales se encontraban a bordo aún peor que los hombres. Al embarcar y desembarcar tienen que soportar ya mucho. Cuando se les embarca por primera vez, se comportan tan feroz e indómitamente que suelen soltarse y caer al agua o al barco, rompiéndose a menudo el cuello y las piernas. Para evitar que pase esto, se les suele embarcar y desembarcar de la siguiente manera: Alrededor de la tripa se les pone una faja de unas seis pulgadas de ancho, a cuyo lado se coloca una gamarra con la cual se tira el animal al aire, de modo que esté siempre bien balanceado, y despues se le baja poco a poco al interior del barco. Durante esta maniobra el caballo está contínuamente pateando y moviéndose hasta que llega al interior del barco, donde suelen colgarlo elásticamente, si

${ }^{21}$ Mämpel, tomo 1, págs. 72 y sig. 
hace mal tiempo. Los animales con experiencia en viajes por mar están ya acostumbrados a tales maniobras y lo soportan todo, salvo unos pocos, que nunca aprenderán a tolerarlo con calma. Nunca deben tumbarse durante el viaje, porque como están mucho tiempo de pie, se quedan tan rígidos que no se podrian levantar sin ayuda ajena.

Cada noche se les cuelga en sus fajas, donde pueden descansar y dormir más o menos cómodamente. Si hace mal tiempo, estos animales padecen del mal de mar, igual que los hombres. No comen nada, bajan sus cabezas y muestran su malestar resoplando fuertemente. Saben exactamente cuándo se les va a liberar de su tortura, de modo que no se mueven cuando notan que van a ser desembarcados. ${ }^{22}$

Estimulado por el gran éxito de su obra, publicó Mämpel, también anónimamente, tres tomos más, donde cuenta la historia de otros compañeros de guerra, cuyos destinos se parecen también al suyo. Los libros se titulan Des Jungen Feldjägers Landsmann unter ähnlichen Schicksalen (tomo 4 de la obra), y Des Jungen Feldjägers Zeitgenosse in preussischen, französischen, englischen und sardinischen Diensten: nach dessen Tagebuche erzählt vom Feldjäger (tomos 5 y 6 de la obra). ${ }^{23}$ En todos los títulos de la obra aparece la palabra Feldjäger, ya que asi se titula el autor a sí mismo. Los seis libros están escritos en primera persona, a pesar de tratarse de "memorias indirectas" a partir del tercer tomo. Sólo por los títulos sabemos de quien trata cada libro: En los dos primeros aparece "Der Junge Feldjäger[...]" en nominativo, lo que anuncia la propia historia del autor. A partir del tercer tomo los títulos empiezan en genitivo "Des Jungen Feldjägers [...]", indicando la relación del Feldjäger con el protagonista, que es en el tercer tomo su compañero de guerra (Kriegskamerad), en el cuarto su compatriota (Landsmann) y en el quinto y sexto su contemporáneo (Zeitgenosse). El Feldjäger y sus compañeros tienen en común que eran muy jóvenes cuando entraron en los diferentes ejércitos y que cambiaron los frentes según las circunstancias. Goethe no escribió prólogos para los tres últimos tomos, pero recomendó en otra ocasión el tomo 4, publicado en 1827:

Si no nos equivocamos, Des Jungen Feldjägers Landsmann, que acaba de publicarse, debe elogiarse aún más [...], de modo que se trata de un caso singular, en que los varios tomos sucesivamente publicados, que normalmente suelen llegar a cansar al lector, se muestran cada vez más interesantes. ${ }^{24}$

Aunque los dos primeros tomos de la obra están dedicados a su propia historia, Mämpel se refiere ya en el segundo tomo, págs. 27-29, a los prisioneros de la isla de Cabrera, cuyos sufrimientos cuenta en el tercer tomo.

\footnotetext{
${ }_{23}^{22}$ Mämpel, tomo 2, págs. 135-137.

23. Damos las gracias a la Universitätsbibliothek München por habernos prestado las microfichas de los tomos 1-4 y a la Sächsische Landesbibliothek Dresden por el préstamo de los tomos 5 y 6. El tomo 5 no trata de España.

Goethe's sämmtliche Werke [...], tomo 31, pág. 324.
} 
La historia de los prisioneros franceses en Cabrera ha sido tratada tanto por la literatura de ficción como por los estudios científicos. En ambos casos los autores se basan en buena parte en las memorias de los supervivientes de esta tragedia. Mientras que la novela Cabrera de Jesús Fernández Santos de 1981 trabaja el tema de forma literaria, Pierre Pellisier y Jérôme Phelipeau optan por un punto de vista más periodístico en su libro novelístico Les grognards de Cabrera de 1979, traducido al español con el título Los Franceses de Cabrera. En cuanto a la literatura científica, destaca el libro del historiador y profesor emérito canadiense Denis Smith titulado The Prisoners of Cabrera. Napoleon's Forgotten Soldiers 1809-1814, publicado en 2001 en Nueva York, porque no sólo se basa en varias memorias francesas y en la literatura secundaria ${ }^{25}$ sino también en muchas fuentes inéditas de varios archivos españoles, franceses e ingleses, aportando así muchos datos nuevos. Además de este libro hay que mencionar los tres capítulos que Miguel de los Santos Oliver dedicó al tema en el segundo tomo de Mallorca durante la primera revolución, publicado en 1901 y reeditado en 1982, donde usa fuentes mallorquinas y algunas memorias. Un estudio, que informa sobre todo de los problemas económicos y sanitarios causados por los prisioneros a las autoridades maliorquinas, fue publicado en 1988 por Miguel Bennásar Alomar. Se titula Cabrera. La Junta Gubernativa de Mallorca y los prisioneros del ejército napoleónico, y se ocupa en buena parte de los fondos destinados a mantener a los prisioneros. Aparte de estos trabajos, Smith cita otros tres libros: La Isla de Cabrera, publicado en 1907 por Pedro Estelrich, que incluye una justificación del trato de los presos por parte de Mallorca en un ensayo, escrito por Jaime L. Garau, titulado Noticias Históricas del Cautiverio de los Prisioneros Franceses en Cabrera, que usa la interesante colección de documentos de la familia Desbrull, que hoy se conserva en el Archivo Municipal de Palma; la tesis doctoral del suizo Théophile Geisendorf-desGouttes Les Archipels Enchanteurs et Farouches: Baléares et Canaries, Vol. 1, Cabrera, L'lle Tragique, de 1936, donde se analiza también la credibilidad de varias memorias; y el libro de Lluís Roura Aulinas L'Antic Règim a Mallorca: Abast de la Commoció dels anys 1808-1814, publicado en 1985, que examina las condiciones sociales y demográficas de Mallorca antes y durante la guerra. ${ }^{26}$

\footnotetext{
25. Véase el relato de la investigación de Denis SMitH: The Prisoners of Cabrera. Napoleon's forgotten Soldiers 1809-1814. Nueva York-Londres (Four Walls Eight Windows) 2001; págs. 183-189.

El mapa de la página siguiente lo hemos sacado de: Rossel Ló VAOUER, Ramo, Notes Históriques de Cabrera. Campos (Roig i Montserrat), 1995.
} 


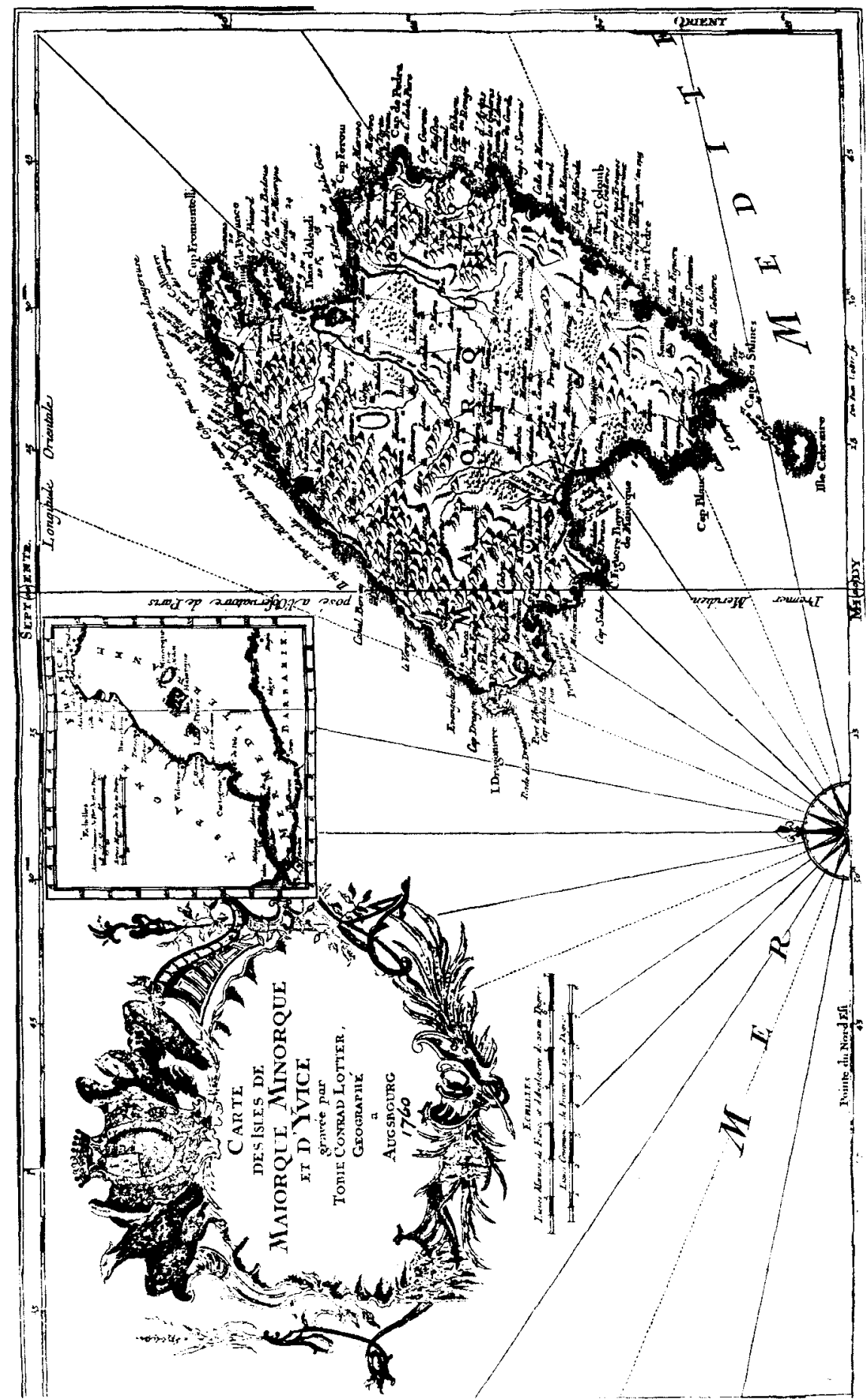


Cabrera, isla deshabitada por la escasez de agua y la aspereza general del terreno, fue el destino final de miles de prisioneros franceses de la batalla de Bailén, después de haber pasado meses horribles en los pontones de la bahía de Cádiz, aunque en la capitulación se les había asegurado la repatriación a Francia, condición que sólo se cumplió con repatriar al general Dupont y a 180 oficiales en septiembre de $1808 .^{27}$ Mientras que según Raymond Carr "los oficiales regulares españoles violaron descaradamente los términos de la capitulación de Bailén", ${ }^{28}$ Denis Smith descubrió en documentos del Foreign Office y de la Royal Navy que los españoles no eran los únicos culpables de esta tragedia y que «the British were crucial participants in the Cabreran misadventure. ${ }^{29}$

Cabrera fue el destino de los soldados rasos y los oficiales de menos categoria. Las autoridades españolas separaron a los oficiales de más categoría para que estos permanecieran en Mallorca. En 1810, después de largas negociaciones diplomáticas, decidieron, junto con las autoridades inglesas, sacar a los oficiales de menos categoría (entre ellos médicos, barberos cirujanos y farmacéuticos) de Cabrera y trasladarlos a Inglaterra, lo que causó una gran desesperación entre el resto de los prisioneros: ${ }^{30}$ "As the ships left Cabrera, the remaining prisoners fell into melancholy [...] The disappearance of the officers marked the moral low point of life on the prison island. [...] It was hardly an exaggeration to say that those who remained were being left to die. ${ }^{31}$

Mientras que algunos autores suponen que hubo unos nueve mil prisioneros en Cabrera, de los cuales sólo tres mil seiscientos saldrían del cautiverio, ${ }^{32}$ Smith habla de un total de unos 11.800 , de los que fueron liberados al final 3.700. Esto no quiere decir que todos los restantes perdieran su vida en la isla, porque muchos capitularon con los españoles o los ingleses, y a principios de 1815 fueron repatriados $1.200 .^{33}$ Por lo tanto, la cifra de diez mil muertos, adelantada por Raymond Carr, es demasiado elevada.$^{34}$ Según Smith, «initial French estimats of about 10.000 dead seem

\footnotetext{
27. SMITH, págs. 28 y sigs. El trato privilegiado a los oficiales era una práctica común.

${ }^{26}$ CARR, Raymond, España 1808-1975. Barcelona (Ariel), 5ª ed, 1990; pág. 115. [1ª ed. española 1969].

SMITH, prólogo, pág. XVIl.

${ }^{30}$ Para más detalles, especialmente sobre las negociaciones entre la Junta de Palma y las autcridades inglesas, véase: SMıTH, pags. 129-143; véase también: BenNásar Alomar, Miguel, Cabrera. La Junta Gubernativa de Mallorca y los prisioneros del ejército napoleónico. Paima (Ajuntament de Palma) 1988; págs. 58 y sig.

${ }^{31}$ SMITH, págs. 141 y sig.

${ }^{32}$ Santos Oliver, Miguel de los, Mallorca durante la primera Revolución. (1808-1814). Palma 1901, págs. 247 y sigs.; y: Pelisisien, Pierre y Phelipeau, Jérôme, Los Franceses de Cabrera 1809 1814. Próloge y traducción de Carlos Garrido. Palma de Mallorca (La Foradada) 2000; prólogo.

${ }^{33}$ SMITH, págs. 166 y sig.. Más información sobre las cifras en SMITH, pág. 209, nota 8

${ }^{34}$ CARR, pág. 115
} 
substancially exaggerated, unless those who died on the hulks in Cádiz are included." 35

En Cabrera se pasaba hambre, tanta hambre que incluso se dio un caso de canibalismo, según nos cuenta en sus memorias el oficial Karl Franz von Holzing (1787-1839), que estuvo prisionero en varias de las islas Baleares:

Durante mi estancia en Palma [1812] se produjo en la isla de Cabrera un caso de canibalismo, que horroriza a toda la humanidad civilizada. A esta isla llegó un nuevo transporte de prisioneros, entre los que figuraba un joven granadero francés cuyo aspecto sano y lozano mostraba todavía la buena alimentación que había tenido cuando era libre. Un polaco, asilvestrado y embrutecido por los horrores del cautiverio, le llevó a una cueva, donde le mató, rompiéndole la cabeza contra una roca. Escondió el cadaver y durante varios días se alimentó con su carne. Descubierto el horroroso crimen, fusilaron al polaco en presencia de todos los prisioneros.

Un español [...] publicó un artículo en la prensa de Palma, mostrando libremente su indignación ante el hecho de que un pueblo que se llama cristiano deje morir de hambre a los prisioneros de guerra. Pero, juzgando estos sucesos, no se debe olvidar que el año 1812 fue un año de hambre. ${ }^{36}$ Ese verano, por ejemplo, murieron diariamente en Madrid de desnutrición hasta 200 hombres. Por eso hay que reconocer el esfuerzo de la Junta de Palma, ya que después de la aparición de ese artículo en la prensa nuestra alimentación mejoró y dicen que también se suavizó la situación de los pobres hombres de Cabrera. $^{37}$

Los prisioneros mismos se esforzaban en ganarse la vida trabajando. Con los escasos medios que tenían labraban la tierra. $Y$ para variar la pobre dieta y ganar algo,

seis de los mejores nadadores iban cada dos semanas, si el tiempo lo permitía, a la isla de Conejera, situada a media hora de Cabrera, donde cazaban una gran cantidad de conejos y golondrinas de mar. Los metían en barriles que a la vuelta tenían que empujar nadando. ${ }^{38}$

Una posibilidad para salir de la miseria fue la capitulación con los españoles o los ingleses:

\footnotetext{
${ }^{35}$ Simith, pág. 167.

${ }^{36}$ En el año 1811 hubo una plaga de langosta. En las memorias de Friedrich von Weech, Badische Truppen in Spanien, 1810-1813 [...], publicadas póstumamente en 1892, pág. 23, leemos: «El año 1811 trajo a España aparte del azote de la guerra otro castigo: la plaga de la langosta, causada por el inmenso calor y una gran y duradera sequía."

${ }^{37}$ HolzING Karl Franz von: Unter Napoleon in Spanien. Denkw, rdigkeiten eines badischen Rheinbundoffiziers (1787-1839). Aus alten Papieren herausgegeben von Max Dufner-Greif. Berlín (Hugo) 1937; págs. 243 y sig. Holzing mismo publicó parte de sus memorias en 1824 bajo el título Meine Gefangennehmung in Spanien, vierjährige Gefangenschaft in Alicante, auf den balearischen Inseln etc.

${ }^{38}$ STRICKER, pág. 131 y sig.
} 
En septiembre de 1811, ocho meses después de la llegada de los alemanes [de la brigada Schwarz] a la isla, vino el capitán de caballería von Alberti, alemán de nacimiento y antes oficial austriaco, que había entrado al servicio de España después de la paz de Viena (octubre de 1809) para poder seguir luchando contra Napoleón, con el fin de alistar prisioneros alemanes para seis nuevos regimientos que estaba formando. Muchos capitularon en seguida, otros permanecieron fieles a su soberano, otros no querían dejar a algún compañero con el que habian forjado una gran amistad y cuya debilidad no le permitía alistarse. Hubo todo tipo de escenas conmovedoras. El día que finalizó la capitulación, el general Wittingham llegó personalmente a la isla. Alberti propuso que había que vestir a los hombres antes de regresar con ellos a Palma, pero el general le contestó: "No, hay que llevarles así a Palma, para que la nación vea cómo ha pecado contra la humanidad." ${ }^{39}$

Muchos de los prisioneros sanos y fuertes se instalaron en Cabrera más o menos cómodamente. Su actividad es ahora objeto de elogio:

[...] establecieron en Cabrera talleres de muchos oficios. Era admirable verles sustituir el escoplo por un cuchilio y el cincel por un clavo afilado, y con estas herramientas esculpir primorosamente figuras de Napoleón, juegos de ajedrez, cajas, anillos de concha, cruces de nácar y otras mil cosas curiosas que se conservan aún en poder de diversas personas. Fabricaron curtidos y, con éstos, zapatos; hicieron redes y demas avios necesarios para la pesca; azogaron espejos; trabajaron perfectamente la pita, la cerda y el pelo; cultivaron los campos $[\ldots]^{40}$

Aunque prácticamente no se podía ni pensar en escapar, "for those whose spirits had not failed, escape remained the everlasting dream ${ }^{41}, y$ se sabe que algunos lo consiguieron. Así, en las memorias del teniente Wilhelm von Schauroth, estacionado con el regimiento Nassau en Barcelona, podemos leer:

En los restos de un barco llegaron hoy al puerto de Barcelona para nuestra gran sorpresa dos franceses que habian estado 28 meses en la Isla de Caprera [sic] como prisioneros de guerra. A la buena ventura habían aprovechado los restos de un barco naufragado para escapar de su miseria. La fortuna estuvo de su lado y un viento favorable les llevó en tres días llenos de peligro al puerto amigo de Barcelona, donde al pisar el suelo se arrodillaron para dar las gracias a Dios por su salvación. ${ }^{42}$

Tanto esta feliz historia como ia buena suerte de! joven Philipp Schwein, referida por Mämpel y que vamos a traducir al final de este estudio, confir-

\footnotetext{
${ }^{39}$ STRICKER, pág. 133.

${ }^{40}$ Bovér, Joaquin Maria, Cabrera. Sucesos de su Historia que tienen relación con la de Francia. Palma (Felipe Guasp) 1847; pág. 18.

${ }^{4}$ SMITH, pág. 148.

${ }^{42}$ SCHAUROTH, pag. 140.
} 
man lo que Denis Smith dice en el prólogo de su mencionado libro: “On Cabrera too there were winners and losers: on one side the fortunate, the strong, the ingenious, the opportunists; on the other the unlucky, the weak, the passive, the unimaginative, the dead. Those few who wrote accounts of their captivity were among the winners. ${ }^{43}$ Son los fuertes, los ganadores, a los que elogia Goethe en su prólogo, mientras que para los debiles, los perdedores, los muertos, no muestra ni compasión. Los franceses mismos tardaron más de treinta años en acordarse de esta tragedia y en homenajear a sus muertos con una estela.

A Cabrera queda una estela de records tan dolenta [...]. Jo, que encara no havia nat, vaig heretar la fascinació per un dolent de veres, que podia competir amb els gegants de les rondalles $i$ amb els éssers malignes que poblaven els meus somnis d'horror. ${ }^{44}$

Esta estela la mandó levantar el Príncipe de Joinville cuando pasó por Cabrera en 1847. Su colocación nos la cuenta Joaquín María Bovér:

Recogidos de antemano los restos mortales de los prisioneros franceses [...], y escogido el local en que se debia elevar el monumento mortuorio, se celebró la ceremonia religiosa acostumbrada en estos casos. [...]. Viéronse derramar muchas lágrimas de los ojos de la oficialidad y tripulacion de la escuadra, y estas lágrimas regaban la tierra que habia sido testigo de tantos infortunios y sinsabores. [...]. Concluida la ceremonia, un viejo de setenta años, que desde niño vive en aquella isla, empezó á contar sucesos desastrosos que habia presenciado durante la permanencia de los franceses en ella, y esta narración aumentó notablemente el dolor y el sentimiento de la numerosa concurrencia. [...] el Ser[enísi]mo. Sr. Príncipe de Joinville dejó sus órdenes y confió el encargo de realizar el proyecto al Sr. D. Julio de Cabarrus. [...] y la diligencia y actividad del Sr. de Cabarrus fueron suficientes para verla [la obra] terminada el 22 de agosto de 1847. [...] Elevado el monumento en el punto de la isla que mejor pueda distinguirse desde una larga distancia [...]. Su construcción sencilla es la que permite un monumento mortuorio, y al mismo tiempo la que requiere un monumento que expuesto al castigo del sol y de las lluvias prometa muchos siglos de duración. ${ }^{45}$

${ }^{43}$ SMITH, pág. XVIII.

${ }^{44}$ SUNYER, Francisca: Viure a Cabrera, lina illa feta a mida. Amb illusiracions de Guillem Oliver Sunyer. Mallorca (Moll), 1993. Damos las gracias por este libro a Nele Stegmann de Detmold, amiga de la autora.

${ }^{45}$ BOVÉ, págs. 19-23. Ilustración de la página anterior: Bovér, pág. 19. Damos las gracias a la Biblioteca Nacional de Madrid por el permiso de publicación. 


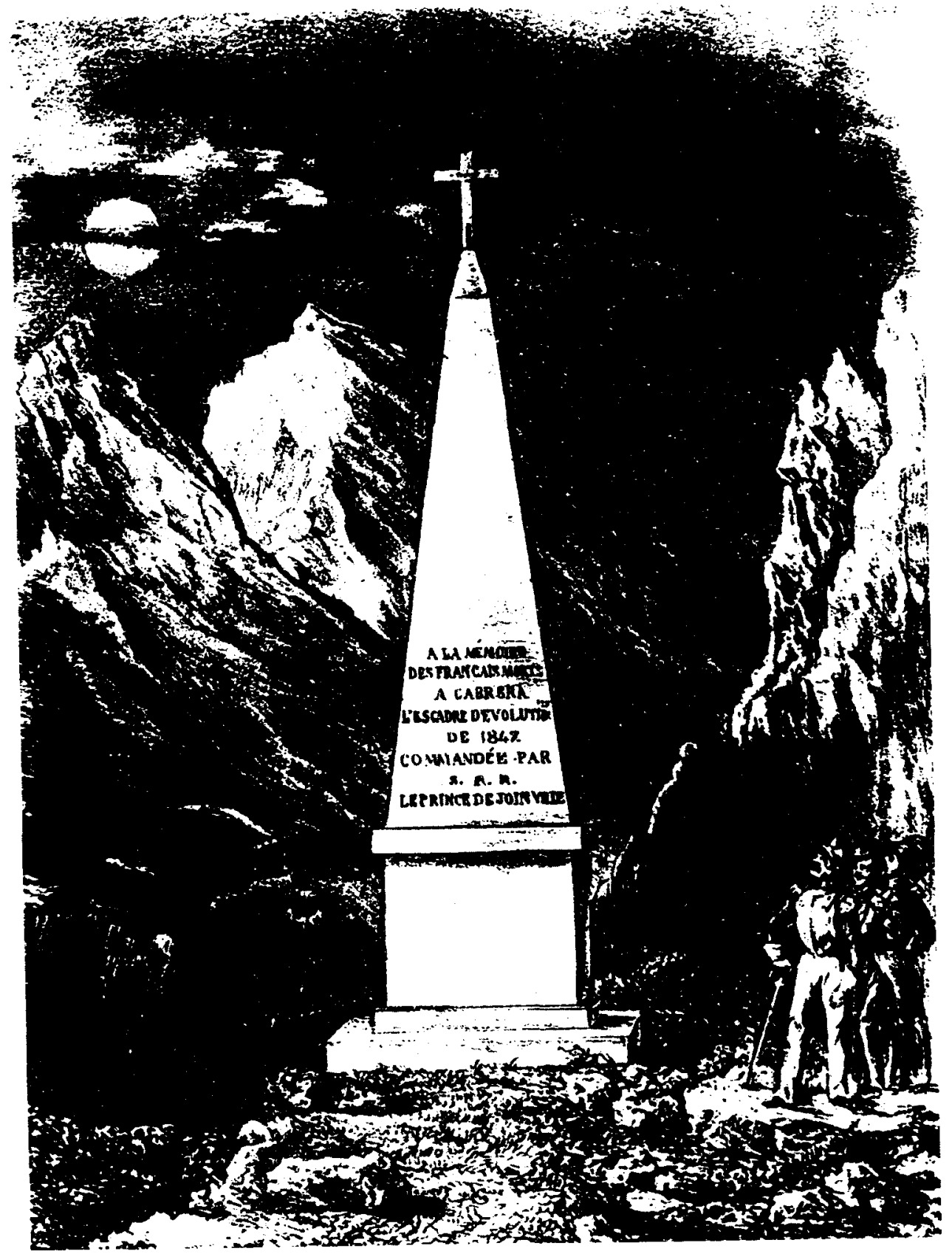


Entre los primeros prisioneros que llegaron a Cabrera en mayo de $1809^{46}$ estaba el joven alemán Philipp Schwein, de 16 años, hijo de un carnicero de Rheinzabern (Speyer), que había sido obligado a alistarse, ya que los territorios a la izquierda del Rhin habian quedado desde 1801 bajo dominio francés. ${ }^{47}$ Toda su historia aventurera, tanto en el ejército francés, que terminó con sus años en Cabrera, como en el inglés, tras su capitulación con los ingleses, que le llevó con el $7^{\circ}$ batallón de la King's German Legion durante varios años a Sicilia e Inglaterra, desde donde acompañó al general Dalrymple hasta China, ${ }^{48}$ la cuenta anónimamente y en primera persona el ya mencionado autor Johann Christian Mämpel, el Feldjäger, en el tercer tomo de su obra, titulado Des Jungen Feldjägers Kriegskamerad gefangen und strandend, immer getrost und thätig.

Mientras que el primer capítulo nos informa de la infancia de Philipp Schwein, los capítulos dos al seis tratan de su estancia en España. Formó parte de las tropas que combatieron bajo el mando del general Dupont y participó en la batalla de Andalucía en la brigada del general Wedel. ${ }^{49}$ Cuenta el incumplimiento de la capitulación del 21 de julio de 1808, cuya condición era la repatriación a Francia:

Como habian prometido embarcarnos en Sanlúcar de Barrameda para llevarnos a nuestra patria desde este país de muerte, todos estábamos llenos de alegria esperando poder escapar. [...] Pero los españoles no cumplieron su palabra. En Sanlúcar nos arrojaron a los pontones y a casamatas malolientes. [...] para más seguridad nos llevaron a Cádiz [...], donde nuestra situación fue aún peor, porque fuimos destinados a los pontones situados en el puerto y en la rada. Nuestros vigilantes eran galeotes indultados y jamás en mi vida he encontrado a personas peores. [...] A ningún esclavo, a ningún animal le trata su amo, por muy duro de corazón que sea, peor que nos trataban a nosotros. Muchos de mis compañeros de infortunio se tiraron al agua para terminar su sufrimiento. En aquel momento también yo me hubiera sentido feliz si hubiera muerto.

\footnotetext{
${ }^{46}$ Según Stricker hubo más tarde otros prisioneros alemanes: «El 14 de enero de 1811 llegaron los prisioneros de la brigada Schwarz después de una travesía de cinco horas desde Palma a la rocosa isla de Cabrera". STRICKER, pág. 125. En las memorias del teniente Wilhelm von Schauroth leemos: «El 23 [septiembre de 1810] llegó la noticia de que habian hecho prisionero al general Schwarz con dos coroneles y 700 oficiales y soldados rasos cerca de Gerona [...] y que les habian trasladado por mar a Tarragona. Como sabia que en estas tropas estaba enrolado mi hermano, esta noticia me llenó de gran tristeza, porque con él ya dos de mis hermanos estaban prisioneros con un destino incierto, mientras un tercero estaba al servicio de la King's German Legion y por lo tanto al lado de nuestro enemigo." Schauroth, pág. 136.

${ }^{47}$ Desde la Paz de Lunéville. De 1794 a 1814 Speyer (Espira) era la capital de un arrondissement francés.

"Schwein regresó a su pueblo natal, donde se casó con la heredera del "Gasthof zum Lamm".

${ }^{49}$ Las memorias del general Karl von Wedel las editó Curt Troeger en 2 tomos en 1911/13 bajo el título de Lebenserinnerungen.
} 
Tras horrorosos meses en los pontones, le llevaron a Mallorca y finalmente a la isla de Cabrera. Las páginas 62 a 83 del libro describen su vida de prisionero alli.

Nos ha parecido interesante traducir esta historia de un superviviente alemán ${ }^{50}$ porque no hay ningún relato traducido por completo al español. El texto inspiró a Goethe las siguentes refiexiones en el prólogo al tercer tomo:

A la suerte se la suele llamar generalmente redonda como una bola por su gran inconstancia. Pero esta comparación se puede interpretar también de otra manera. En caso de estar quieta, la bola se muestra al espectador como algo feliz, armónico, encerrado en si mismo. Por esta razón no puede atraer nuestra atención durante mucho tiempo, igual que la persona dichosa. Todo el bienestar, toda la satisfacción son simples, da igual de donde nazcan. A los felices les abandonamos a sí mismos [...]. La mala suerte la queremos comparar con un prisma, que irrita a la vista, con cuyos aristas se tropieza por todos lados y que no ofrece tranquilidad por ninguna parte al sentimiento. Mientras que la bola atrae a la luz para permanecer en ella dulcemente y lo redondo se nos muestra en suaves sombras y reflejos, el prisma nos manda de cada lado otro brillo, otro oscurecimiento, otros colores, otras sombras y otros reflejos. El ojo inquieto se fija en sus aristas, deseando unir las piezas en dispersión, mientras su atención se mantiene pendiente como atraída por un enigma sin solución.

El motivo concreto que origina estas reflexiones es este pequeño libro. Salvo pocas excepciones sólo describe la desgracia y la mala suerte, el dolor y la desesperación.

No obstante, lo que en un sentido superior da sosiego y resulta consolador y tranquilizador es que las personas que tanto sufrieron y que más de una vez vieron llegar la muerte, al final son capaces de contar todo lo que resistieron y cómo finalmente se vieron a salvo de la más insoportable miseria.

Pero en realidad no fueron salvados, sino que ellos mismos se salvaron. Una fuerza superior favorece a los constantes, los activos, los comprensivos, los ordenados, los regulares, los humanos, los piadosos. Es aquí donde se demuestra la moral del orden mundial en su más espléndida manifestación, aquí donde se apoya directamente al bueno, al valiente.

La constitución burguesa en la desierta playa de Cabrera, la más miserable de las Islas Baleares, se merece el respeto de todos los pensadores como la primera muestra de una razonable constitución de derecho natural. La táctica y la estrategia de los infelices navegantes, de una multitud de hombres encallados en las estértiles dunas, amenazados por las olas en medio del mar nos muestra, en conjunto y pieza a pieza, ejemplos de serenidad natural y moral, de constancia nata y adquirida, de un atrevimiento bien pensado y dirigido a un fin práctico y, de nuevo, después de la inevitable muerte de tantos, la salvación de algunos, que incluso en la peor situación se comportan valiente y humanamente, para finalmente encontrar para su bien a un amigo.

\footnotetext{
${ }^{50}$ Los libros sobre Cabrera mencionan exclusivamente memorias francesas. Sólo un capítulo del libro de Stricker, págs. 125-134, está dedicado a las memorias alemanas.
} 
Nos preguntamos qué puede parecer más glorioso y deseable a la persona corriente. Que individuos como él, tan insignificantes como él, lleguen a ser un ejemplc óptimo al mostrar virtudes que probablemente él mismo podría necesitar en caso de verse implicado al menor descuido en grandes peligros y azares inesperados.

Consideramos que es una grata necesidad recomendar un libro que nos ha inspirado estas reflexiones. Confiamos en que cada lector inteligente pueda sacar provecho de estos destinos tan excepcionales, aunque no tan raros en el curso del mundo.

(Goethe)

Ahora dejemos relatar a Mämpel lo que le sucedió a su compañero Philipp Schwein mientras estuvo prisionero en Cabrera:

[...] Pisamos el suelo de Mallorca, una de las Islas Baleares, y entramos en la capital, Palma, llenos de expectación por lo que nos aguardaba. En realidad no temíamos nada, porque nada podía ser peor que lo que habíamos pasado y todavía estábamos pasando. Nos llevaron a un viejo cuartel, en cuyos muros vacios se perdían nuestros suspiros sin llegar al oído de algún ser compasivo. Nuestra ropa estaba tan andrajosa que algunos sólo se cubrían con harapos. Además estaba totalmente llena de bichos, porque a pesar de nuestros esfuerzos de quitárnoslos de encima de la manera que fuese, no conseguíamos eliminarlos, ya que el aire y el clima de España deben favorecer el brote de estos asquerosos parásitos.

\section{Capítulo Cuatro}

Estancia en Palma. Travesía a Cabrera. Estancia y vida de los presos. Horrorosa hambre y sus consecuencias. Instalación y organización de los presos. Reclutamientos de los españoles e ingleses entre los presos.

De nuevo los españoles intentaron persuadirnos para entrar a su servicio. No obstante, a pesar de toda nuestra miseria, rechazamos las deshonrosas ofertas de sus emisarios y por fin nos dejaron en paz. Pero para no dejarnos siquiera comer nuestro frugal pan, obligaron a los sanos a trabajar en obras públicas. Teníamos que trabajar en los arsenales y ayudar en la construcción de nuevas baterias, 10 que nos convino mucho, porque, a pesar de pasar un hambre terrible, el aire puro y el movimiento nos venían muy bien a todos. Durante estas labores conocí a muchos alemanes, alistados en un regimiento suizo. Muchos de ellos tenían compasión de nosotros, y sobre todo yo les daba mucha pena. A menudo tenían que vigilarnos en nuestros trabajos, y a la hora de la comida siempre compartían sus escasas raciones con nosotros. Sobre todo a mi me alimentaron bastante bien, causando a menudo la envidia de mis compañeros, algo comprensible en tales circunstancias. Así que no me podía quejar y poco a poco ganaba fuerzas. Este buen periodo desgraciadamente no duró mucho, porque la Junta española mandó a todos los presos franceses a otro destino. Al sur de Mallorca está la isla de Cabrera. Su nombre viene de los rebaños de cabras y ovejas que se trasladan alli para pastar en las estaciones en que los rayos del sol todavía no han exterminado la poca hierba y otras plantas. Abandonan la isla cuando el sol hace notar toda su fuerza, de modo que los animales no encuentran más pasto, y también durante el invierno, cuando se desencadenan en sus rocas fuertes huracanes acompañados de nieve y lluvia. En aquel momento la isla estaba total- 
mente despoblada, porque su suelo no es suficientemente fértil para nutrir al ocioso español. A esta isla nos trasladaron para vivir y morir. Yo estaba entre los primeros que la pisaron; tal vez éramos varios miles de hombres. El resto de la compañía de Dupont, o habían muerto, o estaban todavia repartidos en varios hospitales, o andaban dispersos de alguna manera. Nos echaron a tierra igual que un rebaño de cabras u ovejas, nos pusieron unos guardias españoles, nos aprovisionaron a cada uno con pan y verdura para algunos días y nos abandonaron a nuestra suerte. De alguna manera esto nos pareció muy bien, porque ahora podíamos movernos como nos daba la gana, pero la estación en la cual habiamos llegado pronto nos dejó sentir que no teníamos techo. Todo estaba inculto y estéril; sólo de vez en cuando aparecía una hierba entre las piedras debajo de la protección de una roca. Algunos pocos arbustos bajos cubrían de vez en cuando el suelo, donde incluso a veces anidaba un pajarito, que se retiraba asustado cuando nos veía. Con el cielo encima y el mar alrededor, nos encontramos prácticamente enterrados vivos. Una barraca empalizada servia de casa a la guarnición, que nos ignoraba totalmente, porque en huir no se podia ni pensar. Cerca de la isla anclaban algunos barcos ingleses, dispuestos a acercarse en cada momento para exterminarnos en caso de la más mínima revuelta. La primera noche nos arreglamos de la mejor manera posible. pero ya al segundo día se formaron grupos para organizar la preparación de un refugio. La mayoría empezó a quitar ramas de arbustos y a recoger hierba seca que había en abundancia. Las partes más gruesas de las ramas se utilizaban como soportes de las barracas y para excavar el suelo, un trabajo en el cual había que usar antes que nada las manos, sobre todo las uñas, que muy a menudo sangraban. Pero ni siquiera prestamos atención a esto, ya que trabajábamos para nuestro bien. Construimos la nueva colonia no lejos del mar, cerca de una fuente, la única de la isla, cuya agua tenía un sabor salado. La mayoria de nosotros aprobó la propuesta de vigilar estrictamente la fuente y de penalizar la contaminación del agua. No nos faltaban vasos, y muchos tenían todavía los chacós que servían para transportar el agua para la construcción. En seguida todo se puso en movimiento. Algunos construyeron sin cesar, otros buscaron piedras en la arena de la playa con el fin de utilizarlas como herramientas. Se construyeron las barracas dejando cierta distancia entre si, de modo que para cada hogar sobraba un trozo de tierra del que más tarde, después de haberse acoplado mejor, se podía sacar provecho. No obstante, no todos se organizaron tan bien para el futuro. Muchos erraban de una manera salvaje por la isla sin preocuparse de nada más que llenarse su estomago con las cosas más crudas e indigestas. Todos aquellos fueron antes o después presa de la muerte. Asi pasó el verano y en otoño nuestro trabajo se encontró ya bastante avanzado, de modo que nos sentíamos bastante bien cuando por la noche entrábamos en nuestras barracas, donde disfrutábamos de la tranquilidad y el sueño en la agradable hierba seca. Pero de repente nuestra felicidad se interrumpió por un acontecimiento horroroso. Recibíamos nuestros víveres siempre para cuatro días. Los menos precavidos solían comer sus raciones a las pocas horas, de modo que luego tenían que llenar su estómago con lo que fuera y al final pasaban algunos días mucha hambre. Un temporal que duró una semana entera no dejó salir ningún barco del puerto, de modo que el nuestro con los víveres tampoco llegó. La playa estaba cada día llena de hombres mirando con ansiedad hacia Mallorca en espera de ver el barco que les trajera la salvación. Los apagados ojos de los casi muertos de hambre veían en cada ola espumeante el barco tan ansiosamente esperado. Cada nubecita 
blanca en el horizonte la tomaban por una vela, pero las esperanzas fueron siempre vanas y las decepciones se repitieron una y otra vez. Corrian a las barracas, a la roca, a la playa en búsqueda de algo comestible para el estómago, que gritaba pidiendo comida, pero no había nada por ninguna parte. Comían hierba y tierra para llenar el estómago, pero esto no era un buen remedio y muchos murieron. Los sepultaban enseguida en el mar, porque se temía que se los comieran los vivos. Y es verdad que un polaco mató a un coracero para comérselo. Los españoles lo pillaron cuando estaba a punto de comerse las tripas. Como es debido, lo procesaron enseguida y lo fusilaron. En el juicio confesó haberse comido ya antes a dos compañeros. Por fin el temporal amainó y llegó el auxilio pedido a Dios con tantas oraciones. Todo el mundo afluyó al desembarcadero, se repartió todo enseguida y la mayoría se tragó inmediatamente lo recibido, porque esto no se podía llamar comer, y a algunos los mató la ansiedad. Esto no les importó a los españoles, porque así había menos que alimentar. Pero como habia que temer que se repitiesen estos infelices incidentes, que también podían afectar a la guarnición, instalaron un almacén, que siempre tenía víveres para una semana. Pasó el invierno y con él los días tristes, aunque su recuerdo nos quedará para siempre. Menos mal que en Cabrera el invierno es más suave que en mi tierra; si no todos hubiéramos sido presa de la muerte. No obstante, los pocos grados de temperatura nos afectaron mucho, porque estábamos prácticamente desnudos. Aunque en otoño habíamos amontonado una gran cantidad de hierba seca y a veces habiamos encontrado también algo de madera arrojada a la playa, todo esto no era suficiente para mantener un buen fuego. Como no teníamos ollas, asábamos las habas gruesas que nos daban en la ceniza ardiendo. Nuestros cuerpos se asaron también y algunas partes no se distinguían de las de un negro. La primavera trajo nueva vida y nos animó a nueva actividad. Además la colonia se pobló con nuevos presos traídos por barcos ingleses. Algunos de ellos no lo habian perdido todo, tenían todavia ropa e incluso dinero. En muchas barracas habian muerto compañeros, dejando plazas libres. Si un recién llegado quería ocupar su sitio, tenia que entregar una prenda u otro objeto de valor para dárselo al más necesitado de la familia.

Cuando los españoles se dieron cuenta de que había algo de dinero entre nosotros, varios scldados de la guarnición empezaron a negociar con pan, queso, tabaco, etc. De esta manera entró algo de vida en la colonia. Muchos de nosotros tuvieron entonces la idea de adquirir semillas. Además guardábamos siempre algunas de nuestras habas gruesas para sembrarlas en el trozo de tierra que empezamos a labrar, lo que provocó una fuerte lucha por la tierra alrededor de las barracas. Tuvimos que elegir árbitros para terminar las disputas, y este fue el primer paso para tener nuestra propia policía y nuestra propia justicia. Pronto pudimos cosechar el fruto del esfuerzo de haber labrado la tierra, porque nuestras habas crecieron bastante bien. Como este primer intento había salido bien, cultivamos también tabaco. A nuestro esfuerzo de hacernos la vida lo más agradable posible contribuyó considerablemente un nuevo miembro de mi barraca. Era un alemán de Braunschweig. nombrado $\mathrm{H}[\mathrm{an}] \mathrm{s}$, que había estado al servicio de Westfalia. Había conseguido hacer un buen botin en España con la suerte de haber recibido una parte. Le habian capturado cerca de Barcelona y nos contó mucho acerca de las hazañas de los franceses y de sus éxitos. Su paga de entrada fue una moneda de oro, valorada en ocho táleros, que empleamos de la mejor manera. Primero nos aprovisionamos de varios utensilios necesarios, luego compramos algunas mantas e invertimos algo en semillas. El resto lo gastamos en una fru- 
gal comida, es decir en pan para poder por fin saciarnos una vez con este manjar. Desde la mala experiencia del retraso del barco de víveres nos habíamos protegido bastante bien contra el peligro de morir de hambre. Ya no comíamos como antes cada uno por su lado, sino por hogares, lo que nos permitía tener siempre una reserva para cuatro días. Más tarde, nuestra pequeña parcela nos dio más de lo previsto, permitiéndonos ayudar a los demás o cambiar nuestro excedente por otras cosas que necesitábamos. Cada uno mostró la habilidad de sus manos, haciendo una u otra cosa. Varios habitantes de Palma que se habian enterado venían y compraban y asi secundaron nuestro esfuerzo. En una palabra, nuestra colonia de presos prosperaba cada día más. Por todas partes había vida y actividad. Ya se podían distinguir los ricos de los pobres y sólo algunos sufrieron escasez, porque no querían hacer nada. Incluso los españoles se alegraban de nuestro bienestar, fruto de nuestra diligencia.

Los reclutadores ingleses y españoles repetian casi cada semana sus ofertas de entrar a su servicio, diciendo que seguramente no nos iban a librar tan pronto de la isla, porque ambos bandos seguían luchando con dureza. Muchos se dejaban convencer; incluso la mayoría de nuestra familia se alistó, pero yo y mi buen $\mathrm{H}$ [an]s no acabábamos de decidirnos. Poco a poco nuestra barraca se fue vaciando, de tal manera que al final nos quedamos completamente solos en ella. Seguiamos nuestra rutina como antes y no nos encontrábamos ni bien ni mal. Habíamos decidido no acoger a nuevos miembros, porque queríamos seguir viviendo para nosotros lo más pacífica y tranquilamente posible. Nuestra conversación era a meriudo la patria, sobre todo cuando durante las bonitas noches estábamos sentados fuera de nuestra barraca en un banco que habíamos construido de arbustos y césped. Hablábarnos con nostalgia de nuestros seres queridos que vivian tan lejos y que seguramente estaban de luto por nosotros. También a mi amigo te habian sacado del seno de su familia para luchar por Napoleón.

Así pasamos dos años enteros, viendo a muchos ir $y$ venir, pero también a muchos apagarse, porque no todos vivian tan ordenadamente, no todos eran tan sociables y por lo tanto tan felices como nosotros. Algunos eran demasiado perezosos como para establecer y mantener una casa ordenada. Vagabundeaban por la isla casi desnudos, aguantando tanto el más horrible calor como el frío más penetrante, y al final fueron presa de la muerte.

Como ya he dicho, habiamos elegido desde el principio a los más razonables y mayores de nuestros compañeros para actuar de árbitros en el caso de robos o querellas, con el fin de proteger la propiedad de cada uno. Más adelante se confirmó su cargo, y todos los moradores de la isla tuvieron que reconocerlos. Sólo cuando se trataba de crímenes mayores entregábamos a los culpables a las autoridades españolas. Nuestro pequeño estado se ocupaba de muchas cosas: por ejemplo, teníamos también vigilantes cuya obligación era observarlo todo de día y de noche. Todos los propietarios se turnaban en esta obligación de hacer guardia y asumían toda la responsabilidad por los daños. También instalamos un verdadero mercado, a donde cada uno llevaba la verdura o los utensilios que le sobraban para venderlos o intercambiarlos. Pronto hubo también tabernas; de vez en cuando cacareaba una gallina e incluso se podían encontrar animales de compañía, como perros, etc.. Los españoles se ocuparon también del alimento espiritual y nos mandaron un cura, pero en este hombre sólo la sotana era espiritual. No hacía nada más que insultar, injuriar y maldecirnos. Dijo claramente que nosotros al no 
ser españoles jamás llegaríamos al reino de los cielos, porque sólo los españoles eran buenos cristianos. En resumen, el hombre era tan ignorante y estúpido que a pesar de nuestra precaria situación incluso nos daba pena. Sólo doy el ejemplo de su tipo de consuelo. Preguntado una vez sobre cuándo nos liberaría Dios de aquella isla, hundió su bastón en la tierra y dijo: "Cuando este bastón se ponga verde y tenga hojas, entonces se acercará vuestra liberación." Y cuando le pedimos ropa para cubrir nuestra desnudez, nos contestó: "Los lirios en el campo ni siembran, ni cosechan, pero no obstante nuestro padre celestial los alimenta.» Después nos dio la espalda y se fue. Pero cada domingo celebraba misa, a la cual acudiamos sin faltar. ${ }^{51}$

\section{Capítulo Cinco}

\section{Estoy harto de la vida isleña y capitulo con los ingleses. Despedida de Cabrera [...]}

Habian pasado tres años y todavía no teníamos ninguna esperanza de salvación. Apenas si quedaban algunos de los antiguos compañeros que habian llegado conmigo a la isla. Muchos habían muerto en la miseria y el resto, hartos de su desgraciada vida en la isla, habían capitulado con los españoles o los ingleses. Finalmente nos cansamos también nosotros de la vida isleña y decidimos alistarnos a la próxima ocasión. Como no teníamos ganas de servir a los españoles, esperamos a los ingleses, que pronto se dejaron ver. Con un anticipo de cuatro guineas juramos una capitulación por siete años o, en caso de paz, un despido de seis meses después de su conclusión. Vendimos nuestra barraca y nuestro campo al mejor postor por varios pesos españoles e invertimos este dinero en una fiesta de despedida celebrada con los compañeros que se quedaron. Después dijimos adiós a todos los lugares en que a menudo habíamos estado o donde nos habiamos sentado y dejamos con profunda tristeza aquel lugar, donde habíamos sufrido tantos dolores pero también gozado alguna que otra alegría. Llegó el barco para llevarnos a una fragata inglesa. Pero antes de pisarlo nos entregaron ropa nueva, consistiente en una camisa, unos pantalones, una chaqueta de lana y una gorra de cuartel. En seguida nos arrojamos al mar, nos limpiamos con la arena de la playa y salimos con alegría para vestirnos. Jamás en mi vida sentí algo más agradable que este cambio de ropa, que durante varios días me causó un hormigueo por todo el cuerpo. Todos recibimos además tres pesos españoles de anticipo y con esto entramos en el barco, diciendo adiós para siempre a la isla y a nuestros compañeros. [...]

Hemos tomado contacto con algunos episodios de la obra de Johann Christian Mämpel, con unos textos que cuentan la Guerra de la Independencia desde abajo, desde el punto de vista del soldado raso y de la gente

51. El “consuelo" del capellán Damián Estelrich, que voluntariamente estuvo de 1809 a 1814 en la isla, se cita repetidas veces en las fuentes. Sobre su función mediadora entre los prisioneros y las autoridades de Palma, véase: Bennásar Alomar, págs. 69-71. Mämpel se muestra como un buen conocedor de la Biblia, cuando habia con ironía de este consuelo. El Evangelio de San Mateo, por ejemplo, dice: «De la higuera aprended esta parábola: cuando ya sus ramas están tiernas y brotan sus hojas, sabéis que el verano está cerca." 24:32: "Mirad las aves del cielo: no siembran, ni cosechan, ni recogen en graneros; y vuestro Padre celestial las alimenta." 6:26: "Observad los lirios del campo, cómo crecen; no se fatigan, ni hilan." 6:28. 
humilde, y que están llenos de sufrimientos y desgracias. Las penas, las heridas, las enfermedades, las cárceles, la sed, el hambre y la muerte están siempre presentes y nos recuerdan a menudo Los desastres de la guerra de Goya. No obstante, a pesar de todo el horror, la obra está escrita de una manera tan amena, ligera, fresca, inocente y humana que no deja de agradarnos su recomendación por parte de Goethe. 


\section{APÉNDICE}

\section{Relación Bibliográfica}

\section{Anónimos}

Ansichten von Spanien während eines sechsjährigen Aufenthaltes in diesem Lande. Von einem Officier des ehemaligen Rheinbundes. Wiesbaden (Schellenberg) 1814.

Die Artillerie. Oder: Schnell-Belagerung. Oder: Kurze Bemerkungen über die Art des Angriffs bei Ciudad Rodrigo und Badajoz. Berlín 1822.

Das Bataillon Anhalt in Spanien 1810 und in Schleswig 1849. Erzählt von 2 dessauischen Soldaten am Bivouakfeuer auf der Düppeler Höhe. Berlín (Hayn) 1852. [Trata, entre otros, de Alexius Friedrich Christian, Duque de Anhalt-Bermburg, cuyos soldados lucharon en las tropas del Rheinbund].

"Beiträge zur Geschichte des Feldzuges der französischen Armee in Spanien.» (In Auszügen aus dem Tagebuche eines Badenschen Offiziers über seine Feldzüge in Spanien vom Jahre 1808 bis 1813). En: Geist der Zeit. Ein Journal für Geschichte, Politik, Geographie, Staaten- und Kriegskunde (1819) II, págs. 288, 323 y sigs.

«Bruchstücke aus dem Tagebuch eines Feldpredigers auf einer Reise in Portugal und Spanien in den Jahren 1808 und 1809." En: Minerva (1812) I, pág. 387; II, pág. 42; III, págs. 45 y 236.

Erinnerungen eines Legionärs, oder Nachrichten von den Zügen der deutschen Legion des Königs (von England): in England, Irland, Dänemark, der Pyrenäischen Halbinsel, Malta, Sizilien und Italien: in Auszügen aus dem vollständigen Tagebuche eines Gefährten desselben. Hannover (Helwing) 1826.

Erlebnisse und Abenteuer eines Seesoldaten von der Kaiserlich Franz. Garde in Spanien und Russland. 2 tomos. Leipzig (Reclam jung.) 1838.

Fänf Marter-Jahre: Schicksale eines deutschen Soldaten in Spanien und Sicilien. Weimar (Hoffmann) 1834.

Kriegsbibliothek enthaltend die Geschichte der Befreiungskriege in Spanien,Portugal, Russland, Deutschland, Italien und Frankreich v. J. 1808 - 1815. 5 vols. Leipzig (Baumgärtner) 1815-1819. [España: vol. 1].

Kriegsgemälde, Anekdoten und Charakterzüge aus den denkwürdigsten Feldzügen der neuesten Zeit, insbesondere des Jahres 1809. S.I. 1810.

"Neueste Berichte von der Armee in Spanien." En: Berliner Abendblätter 30 (5.2.1811).

Neuestes allgemeines Kriegs-Historienbuch, oder: auserlesene Sammlung der merkwürdigsten wahren Kriegsgeschichten, sonderbaren Charakterzügen, interessanter Auftritte und Nachrichten von den wichtigsten Schlachten und Gefechten, welche sich in den Ländern des nördlichen und sädlichen Kriegsschauplatzes unter den vermischten Kriegsvölkern beyderseitiger Armeen von 1805 bis 1809 zugetragen haben. 3 tomos. Viena 1809-1811.

Schicksale und Abenteuer anhaltischer Krieger in den Jahren 1807 bis 1815. Dessau 1838.

Schicksale Spaniens in der neuesten Zeit, oder Geschichte Spaniens seit der Röckkehr Ferdinands VII. Leipzig 1836.

“Die Schlacht bei Talavera am 27. und 28. Juli 1809.» En: Militär-Wochenblatt 94 (1909). 


\section{Autores por orden alfabético}

BaLlaUf, M[arie], Des Königs deutsche Legion bis zur Schlacht bei Talavera 28. Juli 1809. Ein Gedächtnisblatt für General Ernst Eberhard Kuno Langwerth von Simmern, geb. 20. April 1757, gest. 28. Juli 1809. Hannover (Feesche) 1909.

Barkhausen, Georg Heinrich von, Tagebuch eines Rheinbund-Offiziers aus dem Feldzuge gegen Spanien und während spanischer und englischer Kriegsgefangenschaft 1808-1814. Hrsg. von seinem Enkel [G. Barkhausen]. Wiesbaden (Bergmann) 1900.

[BÄUERLE, Adolf], Spanien und Tyrol tragen keine fremde Fesseln. Wien (Hirschfeld), 1809.

BEAMISCH, Ludlow N., Geschichte der königlich deutschen Legion. Mit Abbildungen, Schlachtplanen und Tabellen. 2 tomos. Hannover (Hahn), 1832/37. [2 ed. 1906].

BELmONT [seudónimo de Heinrich Adolf Schömberg], Erinnerungen an Spanien, belehrenden und unterhaltenden Inhalts. Dresde (Hilscher) 1823.

Bernays, Guillaume, Schicksale des Grossherzogtums Frankfurt und seiner Truppen. Eine kulturhistorische und militärische Studie aus der Zeit des Rheinbundes. Berlín (Mittler), 1882. [Con un mapa de España.]

BERNDT, Richard: “Unter Napoleon in Spanien (1807-1814)" en Gelbe Hefte 15 (1938/39); págs. 528-551.

Bernhard [seudónimo de Hermann Reuchlin], Der deutsche Soldat. Wahre und schöne Geschichten von ruhmwürdigen Taten deutscher Krieger aus neuer und nevester Zeit. 10 tomos. Stuttgart (Scheible) 1849/51.

BleibTREU, Karl, Deutsche Waffen in Spanien. Berlín (Eisenschmidt), 1885.

- Deutsche Waffen in Spanien. Mit Anhang: Kein Glück. Kriegsnovelle aus Napoleonischer Zeit. Berlín (Eisenschmidt), 1897.

- Marschall Soults grösster Schüler. Berlín 1902.

- Wellington bei Talavera (27./28.VII. 1809). Berlín 1904.

Blumröder, August von, Meine Erlebnisse im Krieg und Frieden in der grossen Welt und in der kleinen Welt meines Gemüths. Sondershausen (Eupel) 1857.

Bodenhausen, Carl Bodo von, Tagebuch eines Ordonnanz-Offiziers von 1812-1813, und über seine späteren Staatsdienste. Ed.: Burghard v. Cramm. Braunschweig (Westermann) 1913.

BÖRnER, Carl (Ed.), «Aus dem Kriegstagebuch des anhaltischen Stabsarztes Dr. Kretschmar während der Feldzüge 1809 in Tirol, und 1810 in Spanien» en Jahrbücher för die deutsche Armee und Marine 106 (1898); págs. 38-58, 135-157, 255-276.

BORNSCHEIN, Ernst: Geschichte der merkwürdigen Ereignisse 1806-1810, oder Napoleon an der Weichsel, am Tajo und Inn. Gera 1810.

Brancaglio, Johann Ernst, Neue Kriegs-Scenen aus Spanien, in den Begebenheiten eines Husaren-Officiers, zur Würdigung des spanischen Volksgeistes, nach reinen Quellen bearbeitet v. Verf. der "Stimme d. Unsichtbaren" Leipzig (Kollmann)1824.

Brandt, Heinrich von, Aus dem Leben des Generals der Infanterie Dr. Heinr. v. Brandt. Aus den Tagebüchern und Aufzeichnungen seines verstorbenen Vaters zusammeng. von Heinrich v. Brandt. 3 vols. Berlin, 1869-1882. Vol. 1: Die Feldzüge in Spanien und Russland 1808-1812. Berlín, 1869/70.

- Erinnerungen aus dem spanischen Feldzug. Véase: KIRCHEISEN, Memoiren [...]; págs. 279-426.

- In the Legions of Napoleon: the memoires of a Polish officer in Spain and Russia 1808-13. Londres, 1999.

BRöCKere, Stanislaus von, Memoiren aus dem Feldzuge in Spanien (1808-1814). Hrsg. von seiner Tochter Pauline v. Cybulska. Posen (Heine) 1883. 
Brodrück, Karl, Der Kampf um Badajoz im Frühjahr 1812. Nach den ursprünglichen Quellen und nach Mitteilungen von Augenzeugen. Leipzig (Dyk) 1861.

BUCHER, Ad. W. H., Tagebuch der Belagerung von Gerona im Jahre 1809, als Erläuterung zum Plane dieser Festung. Hildesheim (Gerstenberg) 1812.

- Journal du siège de Gerona en 1809. Av. 1 plan. Hildesheim, 1812.

- Diario del Sitio de la Plaza de Gerona en Cataluña el Año 1809. Traductor Pablo Miranda. S.l. 1814.

BuCHSIEB, Andreas, Denkwürdigkeiten aus dem Spanischen Feldzuge u.der Schlacht bei Waterloo. Erlebnisse und Abenteuer des alten Veteranen Andreas Buchsieb während der J. 1806 bis 1815. Ed.: Paul Brown. Cöln, Leipzig 1867.

CASPARY, Karl Ch.. Erinnerungen aus dem spanischen Feldzuge und aus der englischen Gefangenschatt (1808-1814). Ed.: Karl Esselborn. Darmstadt 1914.

Cramer, Carl Gottlob, Anekdoten, Schreckensscenen und edle Charakterzüge aus der spanischen Insurrection, von einem Augenzeugen. Leipzig, 1809.

- Die Spanier, oder Scenen aus Spaniens neuester Revolutionsgeschichte. Quedlinburg (Basse), 1810.

- Leben und Schicksale Friedrich von Hellborn, eines aus dem spanischen Kriege glücklich

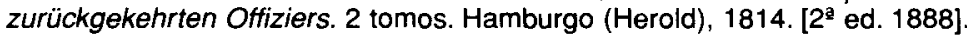

Cramm, Edith von (Ed.), Briefe einer Braut aus der Zeit der Freiheitskriege, 1804-1813. Berlín (Egon Fleischel) 1905. [Cartas de Philippine von Grieshalm, hermana del oficial Grieshalm, combatiente en España].

DEHNEL, H., Rückblicke auf meine Militärlaufbahn in den Jahren 1805 bis 1849 im königl.- preuss. Heere, im Corps des Herzogs von Braunschweig-Oels, im königl.-grossbritann. und im königl.hannov. Dienst. Hannover (Helwing) 1859.

- Erinnerungen deutscher Offiziere in britischen Diensten aus den Kriegsjahren 1805- 1816. Nach Aufzeichnungen und mündlichen Erzählungen zusammengestellt und mit einzelnen geschichtlichen Erläuterungen begleitet. Hannover (Rümpler), 1864.

Dorow, Wilhelm, Erlebtes aus den Jahren 1813-1820. 4 vols. Leipzig, 1845. [España, vol. III].

Egloffstein, H. A. G. von, Castro Lamego, der edle Räuberchef und furchtbare GuerillasAnführer. Mehr Wahrheit als Dichtung. Nordhausen (Fürs) 1825.

EICHELSBACHER, August, “Die Würzburger Truppen in den Kriegen Napoleons I. (1806-1815)." En: Frankenland. 1 (1914); págs. 284 sigs.

ELSNER, Heinrich, Die politischen Zustände Spaniens seit 1808 - 1836. Stuttgart (Erhard), 1836.

Esselborn, K. (Ed.), Die Hessen in Spanien und in englischer Gefangenschaft, 1808-1814. Nach den Erinnerungen von Ludwig Venator, Friedrich und Georg Maurer, Karl Chr. Caspary geschildert. Darmstadt 1912, (Hessische Volksbücher, 13, 14).

- Ludwig v. Grolman. Ein Lebensbild. Darmstadt (H.L. Schlapp) 1910.

- Bilder aus den Aufzeichnungen Karl Friedrich Maurers über den spanischen Feldzug und seine englische Gefangenschaft 1804-1814. Worms 1913.

FELDER, Rcbert M., Der Deutsche in Spanien oder Schicksale eines Württembergers während seinem Aufenthalt in Italien. Spanien und Frankreich, von Rob. M. Felder, ehemaligem Adjudanten der berühmten spanischen Generale Porlier und Mina. 3 tomos. Stuttgart (Hausmann), 1832/35. [2 ed. 3 tomos en 1 vol. 1837].

- Der schwarze Jäger oder Württembergs Krieger in den Jahren 1805 - 1816.3 tomos. Cannstadt 1839.

FÖSTER, Løberecht Gotthelf, Blätter aus der Brieftasche Alexis des Wanderers. Altenburg (Hahn) 1820. 
FreudentHAL, Friedrich, Hannoversche Soldatengeschichten: Vom Harz bis zur Moskwa; unter Napoleons Fahnen; Spanien und Waterloo; der Werber. Bremen 2000.

Friederich, Johann Konrad, Denkwürdigkeiten: oder Vierzig Jahre aus dem Leben eines Todten, genannt auch "der deutsche Casanova". Ed. e introd. de Friedemann Berger. 3 vols. Leipzig, Weimar (Kiepenheuer) 1978. [1 $1^{\text {a }}$ ed. 1848/49. España: vol. 2, págs. 343-460]

- Abenteuer unter fremden Fahnen: Erinnerungen eines deutschen Offiziers im Dienste Napoleons. Berlín 1990, [Nueva edición de la obra anterior].

GeISSLER, Carl, Denkwürdigkeiten aus dem Feldzuge in Spanien 1810 und 1811 mit dem Herzgl.Sächs-Weimar. Contingent. Aus vergilbten Pergamenten. Leipzig (Wiegand) 1910. [1"a ed. Weimar 1830].

GERSDORFF, Carl August von, Vorlesungen über militärische Gegenstände, als erste Anleitung zum Studium des Kriegswesens. Zum Studium des Kriegswesens im Geist der Zeit überhaupt und der Kriegsgeschichte insbesonders. Dresde, Leipzig 1826. [2ª ed. 1827].

Gerson, Georg Hirsch, ber den Hospitalbrand, nach eigenen während des spanischen Befreiungskrieges und in Belgien gemachten Erfahrungen. Hamburgo (Campe) 1817.

Grolmann, Karl von, Leben und Wirken des Generals der Infanterie und kommandierenden Generals des V. Armee Korps Karl von Grolmann. Ritter des hohen Ordens vom Schwarzen Adler. Ed.: E. v. Conrady, General der Infanterie. Berlín (Mittler) 1896.

Grolman, Ludwig von, Tagebuch eines deutschen Offiziers über seinen Feldzug in Spanien 1808. Ed.: P. J. Rehfues. Nürnberg 1814.

- Aus dem Tagebuche eines deutschen Offiziers über seinen Feldzug in Spanien 1808. Véase: Kircheisen, Memoiren [...]; págs. 25-187.

[HARtmann, Julius von], Der königlich hannoversche General Sir Julius v. Hartmann. Eine Lebensskizze mit besonderer Berücksichtigung der von ihm nachgenlassenen Erinnerungen aus den Feldzügen auf der pyrenäischen Halbinsel usw. von 1808 bis 1815. Hannover (Hellwig) 1858. [2 $2^{\mathrm{a}}$ ed. Berlín 1901].

- Erinnerungen eines deutschen Offiziers. 2 vols. 1885.

- Tagebuch-Aufzeichnungen von November, Dezember 1811 in Spanien, des Hannoverschen Generals von Hartmann. Mit einer Lebensskizze des Verf. v. Heinr. v. Sybel. Berlín (Mittler \& Sohn) 21901.

Heidenkamp, Friedrich, «Briefe des Paderborner Bäckergesellen Friedrich Heidenkamp. Füssilier im 2. Französischen Linienregiment, aus den napoleonischen Feldzügen in Spanien und Russland 1809-1813." Ed: P. Fürstenberg. Paderborn. En: Westfälisches Volksblatt 65 (¿1865?).

HERGENHAHN, F, Antheil der herzoglich-nassauischen Truppen am spanischen Kriege 1808- 14. Wiesbaden 1840.

Heusinger, C: Ansichten, Beobachtungen und Erfahrungen, gesammelt während der Feldzüge in Valencia und Catalonien in den Jahren 1813 und 1814 mit Bezugnahme auf die Operationen der verbündeten englisch=sicilianisch=spanischen Armeen. Braunschweig (Meyer) 1825.

- Europäische Biider aus den Land- und Seefahrten eines britischen Militärs während der Ḱreuzzüge gegen Napoleon. Jena 1841.

- Welthilder. Militärische Erinilerungen. Hannover (Kius) 1848.

- Bilder aus den Freiheitskämpfen des 19. Jahrhunderts. 4 vols. Leipzig (Wigand) 1863- 67.

HOHENHAUSEN, Leopold von (Ed.), Biographie des Generals von Ochs. Kassel (Luckhardt) 1827. [Sobre las tropas de Westtalia].

Holleben, A. von (Ed.), Erinnerungen an Eugen und Moritz von Hirschíeld aus Deutschland und Spanien. Zusammengestellt von einem 80-jährigen Veteranen des Yorkschen Corps vom LeibRegimente. Berlín 1863. 
HolzENTHAL, Georg, Briefe über Deutschland, Frankreich, Spanien, die balearischen Inseln, das südliche Schottland und Holland, geschrieben in den Jahren 1809-14. Con 2 grabados. Berlín (Rücker) 1817.

Holzing, Karl Franz von, Meine Gefangennehmung in Spanien, vierjährige Gefangenschaft in Alicante, auf den balearischen Inseln, etc. Freiburg 1824.

- Unter Napoleon in Spanien: Denkwürdigkeiten eines badischen Rheinbund-Offiziers 17871839, Karl Franz von Holzing. Aus alten Papieren herausgegeben von Max Dufner-Greif. Berlín (von Hugo) 1937.

ISENBART, Wilhelm, Geschichte des herzogl. nassauischen 2. Regiments, Stamm des k. preuss. 2. nassauischen Infanterie-Regiments Nr. 88, 1808-1866. Berlín (Mittler) 1891. [2 ed. 1903].

JACOBS, G., Geschichte der Feldzüge und Schicksale der Gotha-Altenburgischen Krieger in den Jahren 1807-1815. Altenburg 1835.

KanNICHT, Joachim, Und alles wegen Napoleon. Aus dem Kriegstagebuch des Georg von Coulon, Major der Königlich Deutschen Legion, und den Briefen seiner Frau Henriette 1806-1815. Koblenz (Bernard \& Graefe) 1986.

KIRCHEISEN, Friedrich Max (Ed.), Memoiren aus dem spanischen Freiheitskampfe 1808-1811. Ludwig v. Grolman - Alb. Jean Michel Rocca - Moyle Sherer - Heinrich v. Brandt - Henri Ducor - Don Juan Andrés Nieto Samaniego. Hamburgo (Gutenberg) 1908. (Bibliothek werthvoller Memoiren, Bd. 7).

- (Ed.), Wider Napoleon. Ein deutsches Reiterleben, 1806-1815. 2 vols. 41917.

KLENK, August, Militärisches Tagebuch meiner Reise durch Frankreich, des Feldzugs in Spanien nebst Rückreise durch Frankreich nach Deutschland mit dem Subsidien- Bataillone der grossherzogl. Frankfurter Truppen. Frankfurt a.M. (Bernhard Körner) 1816.

KnAUTH, Christian, Spanisches Kriegstagebuch. Feldzug in Katalonien 1810. Ed.: O. Bessenrodt. Gotha 1931.

KOLB, Richard, Freiherr August v. Kruse. Ein Lebensbild. Wiesbaden 1890.

- Unter Nassaus Fahnen. Geschichte des herzogl. nass. Officierscorps 1803-1866. Wiesbaden (Roemer) 1903.

KORTZFLEISCH, Das Herzog Braunschweigerische Infanterieregiment. Tomo 1: Das Englisch Braunschweigerische Infanterieregiment bis 1814. Braunschweig 1896.

KaEhBiel, Heinrich, "Erlebnisse eines vor 100 Jahren in Spanien gefallenen Donnersberger, des Heinrich Krehbiel vom Weihershof.” En: Nordpfälzer Geschichtsblätter. (1910); págs. 22 y sigs.

KRIEG von Hochfelden, Wilhelm, Geschichtliche Darstellung sämmtlicher Begebenheiten und Kriegsvorfälle der Grossherzl. Badischen Truppen in Spanien von 1808 bis Ende 1813. Freiburg i. Br. (Herder) 1823. [Con un mapa de España].

KRUG, Wilhelm Traugott, System der Kriegswissenschaften und ihrer Literatur, enzyklopädische dargestellt. Nebst zwei militärisch-politischen Abhandlungen. Leipzig 1815.

LANG, Karl, "Die badischen Truppen in Spanien in den Jahren 1808-1814." Karlsruhe (Gutsch) 1910. (Beilage zu dem Programm des Grossherzogl. Gymnasiums zu Karlsruhe 1909/10). Y en: Militär-Wochenblatt. Berlín (1911); págs. 103 y sigs.

LANGER, Johann, Gemälde von Spanien und seinen Einwohnern. Viena 1812.

LangWerth von Simmern, Heinrich, Aus Krieg und Frieden. Kulturhistorische Bilder aus einem Familienarchiv. Wiesbaden (Deffner) 1906.

LEONHARDI, Christian Gottlob, Die Belagerung von Ciudad Rodrigo und Almeida. Leipzig 1817.

- Die Belagerung von Saragossa 1808 und 1809. Leipzig 1817.

- Die Belagerung von Tortosa im Jahre 1810. Leipzig 1817.

- Zweyte Belagerung von Saragossa vom 21. Dec. 1808 bis zum 21. Feb. 1809. Leipzig 1817. 
LINDAU, Friedrich, Erinnerungen eines Soldaten aus den Feldzügen der königlich-deutschen Legion. Hannover (Helwig) 1846.

- Kriegsfahrten von Jena bis Belle-Alliance: Erinnerungen eines Soldaten der englischdeutschen Legion in Deutschland, England, Portugal, Spanien, Frankreich und den Niederlanden. Ed.: Hermann Lüders. Leipzig (Voigtländer) 1898. (Biographische Volksbücher 36-43).

LINNEBACH, Karl (Ed.), Denkwürdigkeiten der Befreiungskriege. Tomo VI de Bibliographisches Repertorium. Berlín 1912.

LüTzow, Baron von, Trois lettres inédits du Baron de Luetzow a Sir Francis d'lvernois sur la guerre d'Espagne (1810-1812). Ed.: O. Karmin. Paris 1914.

MAAG, Albert: Geschichte der Schweizertruppen im Krieg Napoleons I. in Spanien und Portugal (1807-1814). 2 vols. Biel 1892/93.

[MÄMPEL, Johann Christian], Der Junge Feldjäger in französischen und englischen Diensten während des spanisch-portugiesischen Kriegs von 1806 bis 1816. Eingeführt durch J. W. von Goehte. 3 tomos. Leipzig (Fleischer) 1826. [2 $2^{\mathrm{a}}$ ed. Leipzig 1846].

- The adventures of a young rifleman, in the French and English armies, during the war in Spain and Portugal, from 1806 to 1816. Londres 1826.

- Des Jungen Feldjägers Kriegskamerad gefangen und strandend, immer getrost und thätig. Eingeführt von Goethe. Leipzig (Fleischer) 1826. [Título del tomo 3 de la obra anterior].

- The Young Rifleman's Comrade. - A Narrative of his Military Advantures, Captivity and Shipwreck. Preface by Goethe. Philadelphia 1827.

- Des Jungen Feldjägers Landsmann unter ähnlichen Schicksalen. Leipzig (Fleischer) 1827. [Título del tomo 4].

- Des Jungen Feldjägers Zeitgenosse in preussischen, französischen, englischen und sardinischen Diensten: nach dessen Tagebuche erzähit vom Feldjäger. 2 vols. Braunschweig 1831. [Título de los tomos 5 y 6 ].

[MAURER, Georg Philipp], Einige Erinnerungen der Hessen aus dem Kampfe auf der Pyrenäischen Halbinsel in den Jahren 1808 bis 1812. Den zur 25-jährigen Gedächtnisfeier des Kampfes zu Badajoz am 6. April 1837 versammelten Kriegskameraden zum Andenken übergeben, Darmstadt, im April 1837. Darmstadt 1918 (Hessische Biographien). Y en: Quartalblätter des Hist. Ver. f. d. Grossh. Hessen 5 (1929).

MaURIcıO, "Beyträge zur Geschichte des Volkskrieges in Spanien.» En: Geist der Zeit 1(1817); págs. 149-160.

OcHS, A. L. von, Betrachtungen über die nevere Kriegskunst, über ihre Fortschritte und Veränderungen und über die wahrscheinlichen Folgen, welche für die Zukunft daraus entstehen werden. Kassel (Krieger) 1817.

OMPTEDA, Christian Friedrich Wilhelm von, Ein hannoversch-englischer Offizier vor hundert Jahren, Christ. Fried. Wilh. Freiherr von Ompteda, Oberst in der Königlich Deutschen Legion 26. November 1765 bis 18. Juni 1815. Leipzig 1892.

- In the King's German Legion: memoirs of Baron Ompteda, colonel in the King's German Legion during the Napoleonic wars. London 1894.

POTEN, Bernhard von, Des Königs deutsche Legion von 1803 bis 1816. Darstellung ihrer inneren Verhältnisse. Berlín (Mittler) 1905. Y en: Beiblatt zum Militär-Wochenblatt 11 (1905).

- Ein Reiteroffizier vor hundert Jahren. Berlín (Mittler) 1907.

REhfues, Philipp Joseph (Ed.), “Der Krieg in Spanien und Portugal.» En: Europäische Annalen (1811); págs. 207-241.

- (Ed.): Tagebuch eines deutschen Offiziers über seinen Feldzug in Spanien im Jahr 1808. Nürnberg (Riegel)1814. [Véase: Ludwig v. Grolman]. 
RIGEL, Franz Xaver, Der Siebenjährige Kampf auf der Pyrenäischen Halbinsel vom Jahr 1807 bis 1814, besonders meine eigenen Erfahrungen in diesem Kriege nebst Bemerkungen über das Spanische Volk und Land. 3 tomos. Rastatt 1819 [tomo 1 con 2 y tomo 2 con 6 grabados] y 1822 [tomo 3 con 1 grabado y 3 planos].

- Erinnerungen aus Spanien. Aus den Papieren des Verfassers des Siebenjährigen Kampfes auf der Pyrenäischen Halbinsel von 1807 bis 1814. Mit acht Original-Abbildungen echt Spanischer Nationaltrachten. Mannheim (Schwan und Götz) 1839. [Con ocho grabados].

- Die Belagerung von Valencia durch die Franzosen, während des Befreiungskrieges der Spanier vom Jahr 1808 bis 1814, nebst ausführlichem Belagerungsplan. Rastatt 1819. [2 ed. Mannheim 1843].

- Der Kampf um Tarragona während des Befreiungskrieges der Catalonier von 1808 bis 1814. Mit 1 Plan. Rastatt 1823 [Con un plano]. [ $2^{\mathrm{a}}$ ed. Karlsruhe 1824].

- [Traductor]: Tagebuch der Operationen der Armee von Catalonien in den Jahren 1808 und 1809 unter den Befehlen des Generals Gouvion Saint-Cyr, oder Beiträge zur Geschichte des spanischen Krieges. Darmstadt (Heyer) s.a.

ROESSLER, Aifred von, Geschichte des königl. preussischen 1. Nassauischen Infanterie- Regiments Nr. 87 und seines Stammes, des herzogl. Nassauischen 1. Infanterie-Regiments, 1809-1874. Im Auftrage des Regiments nach den vorhandenen Quellen zusammengestellt. Berlín (Mittler) 1882. [Con 10 mapas y planos].

- "Vergleich des Feldzuges 1809 am Tajo mit den Kampfen an der Loire 1870-71." Berlín 1888. (Beiheft zum Militär-Wochenblatt).

- "Die Operationen Wellingtons und Soults 1809 und 1812 in ihrer strategischen Parallele." Berlin 1894. (Beiheft zum Militär-Wochenblatt).

RUEDER, Friedrich August, Geschichte des Nationalkrieges auf der Pyrenäischen Halbinsel unter Napoleon (1807-1814). Leipzig (Heinrichs) 1829.

[SCHÄFFER, Conrad Rudolf von]: Denkwürdigkeiten aus dem Leben des Freiherrn C. R. von Schäffer, oder Beiträge zur politischen und Kriegsgeschichte unserer Zeit. Mit dem Bildnis des Generals und den Schlachtplänen von Medellin, Almonacid, Mesa de Ibor, Arenas. Ed.: Georg Muhl. Pforzheim 1840.

- Unter Napoleons Fahnen in Spanien (1808-1809), aus den Erinnerungen eines deutschen Generals. Ed.: Karl Brunner. Berlin (Scherl) 1911.

[Schaumann, August Ludof Friedrich]: Kreutz- und Querzüge von August Ludolf Friedrich Schaumann aus Hannover. Deputy Assistant Commissary General in englischen Diensten. Ed.: Conrad von Holleuffer. 2 vols. Leipzig (Brockhaus) 1922.

- On the Road with Wellington: The diary of a war commissary in the Peninsular Campaigns. London 1924. [2a ed. 1999].

SCHAUROTH, Alexander Freiherr von (Ed.), Im Rheinbund-Regiment der Herzoglich Sächsischen Kontingente Koburg=Hilaburghausen=Gotha=Weimar während der Feldzüge in Tirol, Spanien und Russland 1809-1813. Nach den Aufzeichnungen des damaligen Leutnants Wilhelm Freiherr v. Schauroth zusammengestellt. Berlín (Mittler) 1905.

SCHEPELER, Andreas Daniel Berthold von, Geschichte der Revolution Spaniens und Portugals und besonders des daraus entstandenen Krieges. 3 vols. Berlín (Mittler) 1827.

SCHNEIDAwIND, Franz Joseph Adolf, Geschichte des Krieges der Franzosen auf der pyrenäischen Halbinsel unter Kaiser Napoleon. 18 vols. Darmstadt 1838-1843.

SCHUSTER, Joseph (Ed.), Das Grossherzoglich würzburgische Infanterie-Regiment (jetziges 12. Inf.-Regt. Prinz Arnulf) in Spanien 1808-1813, eine Kriegs- u. sanitätsgeschichtliche Jahrhunderterinnerung. München (Zipperer) 1900. [ $2^{2}$ ed. 1909].

SCHWARTZE, Karl, Wahre und abenteuerliche Lebensgeschichte eines Berliners, der in den Kriegsjahren 1807 bis 1815 in Spanien, Frankreich und lialien sich befand. Hrsg. Mit Nachw. und Anm. vers. v. Alexander von Gleichen-Russwurm. München (Drei Masken Verlag) 1921. [Con 10 grabados]. 
SCHWEPPE, Geschichte des oldenburg. Dragoner-Regiments Nr. 19. Berlín (Mittler) 1879. [Trata, entre otros, del oficial August von und zu Egloffstein].

SCHWERTFEger, Bernhard Heinrich (Ed.), Der kgl. hannover. Generalleutnant August Friedrich Freiherr v.d. Busche-Ippenburg. Ein Soldatenleben aus bewegter Zeit. Unter Benutzung hinterlassener Aufzeichnungen aus den Jahren 1793-95, 1805-1815. Hannover, Leipzig 1904.

- Geschichte der königl. Deutschen Legion von 1803 - 1816. 2 vols. Hannover (Hahn) 1907.

- Wellingtons Operationen von Vitoria bis Toulouse 1813/1814. Berlín 1911.

SIMON, J.N., Kriegs-Abenteuer und Erlebnisse in: Deutschland, der Schweiz, Spanien, Russland und Frankreich: während des Zeitraums von 1805-1815. Bevorwortet von A. v. Rff. Mit e. (lith.) Charte v. Catalonien. Oldenburg (Schulze) 1849.

SPORSCHIL, Johann, Feldzug der Engländer, Spanier und Portugiesen gegen die französischen Armeen der Pyrenäen und von Aragonien im Jahre 1814. Braunschweig (Westermann) 1842.

StafF, H. von, Der Befreiungskrieg der Katalonier in den Jahren 1808 bis 1814. Con 1 mapa y 2 planos. Breslau (Josef Max) 1821.

STRASS, Carl Friedrich Heinrich [seudónimo de Otto von Deppen], Die Eroberung von Saragossa oder Ines und Etienne. Leipzig 1828.

Stricker, Wilhelm, Die Deutschen in Spanien und Portugal und den spanischen und portugiesischen Ländern von America. Ein Beitrag zur Geschichte der Deutschen ausser Deutschland. Leipzig (Gustav Mayer) 1850. [Págs. 62-161].

TeCklenburg, August, Mit der kgl. Deutschen Legion wider Napoleon. Göttingen 1913. (Geschichtsquellen für grundl. und erlebendes Lesen im Geschichtsunterricht, fasc. 6).

TElCHMüLlER, W., Geschichte des herzoglich braunschweigischen Leibbataillons und seines Stammes. Braunschweig 1858.

VOLKMANN, "Wanderungen durch Spanien und Portugal im Gefolge der französischen Armee." En: Minerva (1813) III, 222; IV, 21. Y en: Geist der Zeit (1816) II, 421.

[WACHHOLTZ, Friedrich Ludwig von], Aus dem Tagebuch des Generals Fr. L. v. W. Ed.: C. Fr. v. Vechelde. Braunschweig 1843. [Utilizado por W. Teichmüller en: Geschichte des herzoglich braunschweigischen Leibbataillons ...].

- Auf der Peninsula 1810 bis 1813. Kriegstagebuch. Im Auszug herausgegeben. Braunschweig 1818. Y en: Militär-Wochenblatt (1907) Beiheft 8-9.

- Kriegstagebuch des Generals Friedrich Ludwig v. Wachholz. Im Ausz. hrsg. v.H[ilmar] Louis] v. Wachholtz. Mit Skizzen. Berlín (Mittler) 1907.

WACHSMANN, Karl von, Erzählungen und Novellen. S.I. 1830-34 y 1836-39. [El autor tomó parte en las campañas de España y publicó después cuentos románticos como El último suspiro del moro, etc.].

WEDEL, Karl von, Précis des opérations militaires en Espagne, pendant les mois de juin et juillet 1808, avant la capitulation du Général Dupont, a Baylén et a Andújar. París 1823.

- Mémoires militaires du Général Comte de Vedel sur la campagne d'Andalousie en 1808. París 1824.

- Lebenserinnerungen. Ea.: Curt Troeger. Ter tomo: 1783-1810. $2^{9}$ tomo: 1810-1858. Berlín (Mittler) 1911/13.

WEECH, Friedrich von, Badische Truppen in Spanien, 1810-1813. Nach den Aufzeichnungen eines badischen Offiziers [Leonhard Rückert]. Karlsruhe (Braun) 1892. (Badische Neujahrsblätter, BI. 2).

WERNER, H. S. von, Südeuropäische Kriegsgemälde aus den Jahren 1806-1816 nach Selbsterlebnissen niedergeschrieben. Berlín (Wolft \& Co.) 1844.

WICHEDE, Julius von (Ed.), Erinnerungen eines alten Husaren-Officiers aus den Jahren 1802 bis 1815. 3 tomos. Berín 1863. 
WILHELM von Baden, Denkwürdigkeiten aus den Feldzügen 1809 - 1815. Karisruhe 1864.

WISSEL, Ludwig von, Ruhmwürdige Taten, welche in den letzten Kriegen von Unteroffizieren und Soldaten der engl.-deutschen Legion und der hannov. Armee verrichtet sind. Hannover (Helwing) 1846.

Witzleben, Karl August Friedrich von, "Die Legende von San Domingo de la Calpada. Erinnerungen aus meinem Kriegsleben in Spanien" en Der Gesellschafter. $42-45$ (1822).

- “Der Pfarrer von Villarcajo. Erinnerungen aus meinem Kriegsleben in Spanien" en Der Gesellschafter. 118-120 (1822).

- Scenen aus Spanien. Reiseabentheuer. Tomo XII de Sämmtliche Schriften. Dresde 1835.

YoRCK, Graf Wartenburg, Hans David Ludwig von, Napoleon als Feldherr. 2 vols. Berlín 1885.

ZEIDLER, L. Der spanische Feldzug des Bataillons Anhalt im J. 1810. Zerbst (Römer) 1844.

Zimmermann, P., Erinnerungen aus den Feldzügen der Bergischen Truppen in Spanien und Russland. Den Gefährten jener verhängnisvollen Zeit gewidmet. Düsseldorf (Stahl) 1840. [2 ed. 1842]. 